ARTICLE

\title{
Hydrogen spillover in complex oxide multifunctional sites improves acidic hydrogen evolution electrocatalysis
}

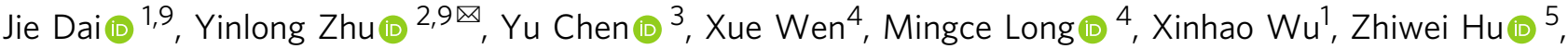 \\ Daqin Guan (1) 1, Xixi Wang ${ }^{1}$, Chuan Zhou', Qian Lin'², Yifei Sun ${ }^{6}$, Shih-Chang Weng ${ }^{7}$, Huanting Wang (1) ${ }^{2}$, \\ Wei Zhou (i) ${ }^{1} \&$ Zongping Shao (1) ${ }^{1,8}$
}

Improving the catalytic efficiency of platinum for the hydrogen evolution reaction is valuable for water splitting technologies. Hydrogen spillover has emerged as a new strategy in designing binary-component $\mathrm{Pt}$ /support electrocatalysts. However, such binary catalysts often suffer from a long reaction pathway, undesirable interfacial barrier, and complicated synthetic processes. Here we report a single-phase complex oxide $\mathrm{La}_{2} \mathrm{Sr}_{2} \mathrm{PtO}_{7+\delta}$ as a highperformance hydrogen evolution electrocatalyst in acidic media utilizing an atomic-scale hydrogen spillover effect between multifunctional catalytic sites. With insights from comprehensive experiments and theoretical calculations, the overall hydrogen evolution pathway proceeds along three steps: fast proton adsorption on $\mathrm{O}$ site, facile hydrogen migration from $\mathrm{O}$ site to Pt site via thermoneutral La-Pt bridge site serving as the mediator, and favorable $\mathrm{H}_{2}$ desorption on Pt site. Benefiting from this catalytic process, the resulting $\mathrm{La}_{2} \mathrm{Sr}_{2} \mathrm{PtO}_{7+\delta}$ exhibits a low overpotential of $13 \mathrm{mV}$ at $10 \mathrm{~mA} \mathrm{~cm}{ }^{-2}$, a small Tafel slope of $22 \mathrm{mV} \mathrm{dec}^{-1}$, an enhanced intrinsic activity, and a greater durability than commercial Pt black catalyst.

\footnotetext{
${ }^{1}$ State Key Laboratory of Materials-Oriented Chemical Engineering, College of Chemical Engineering, Nanjing Tech University, Nanjing 211800, China. ${ }^{2}$ Department of Chemical Engineering, Monash University, Clayton, VIC 3800, Australia. ${ }^{3}$ Monash Centre for Electron Microscopy, Monash University, Clayton, VIC 3800, Australia. ${ }^{4}$ School of Environmental Science and Engineering, Key Laboratory for Thin Film and Microfabrication of the Ministry of Education, Shanghai Jiao Tong University, Shanghai 200240, China. ${ }^{5}$ Max Planck Institute for Chemical Physics of Solids, Nothnitzer Strasse 40, 01187 Dresden, Germany. ${ }^{6}$ College of Energy, Xiamen University, Xiamen 361102, China. ${ }^{7}$ National Synchrotron Radiation Research Center, 101 Hsin-Ann Road, Hsinchu 30076, Taiwan. ${ }^{8}$ WA School of Mines: Minerals, Energy and Chemical Engineering, Curtin University, Perth, WA 6845, Australia. ${ }^{9}$ These authors contributed equally: Jie Dai, Yinlong Zhu. 凶email: yinlong.zhu@monash.edu; shaozp@njtech.edu.cn
} 

ever-increasing environmental issues has raised great concerns about the exploitation of renewable energy sources (e.g., solar and wind power) ${ }^{1,2}$. To overcome the intermittent nature of the renewable energy, an attractive prospect is to store them in the form of chemical bonds in certain molecular fuels ${ }^{3,4}$. Among various chemical fuels, hydrogen $\left(\mathrm{H}_{2}\right)$ has been pursued as the future sustainable energy alternatives to fossil fuels in view of high gravimetric energy density and carbon-free characteristics $^{5-7}$. Therefore, finding a way to produce hydrogen efficiently is crucial for the future hydrogen economy. Electrochemical water splitting powered by renewable energy offers a cost-effective and promising approach for clean hydrogen production with high purity ${ }^{8-10}$. Water splitting in acidic solid polymer electrolytes is more efficient than alkaline electrolysis because it holds some notable superiority such as greater energy efficiency, higher current density, lower crossover of gases and more compact system design ${ }^{11,12}$. As the cathodic reaction in water splitting, the hydrogen evolution reaction (HER) is sluggish and requires an efficient electrocatalyst to expedite the rate. Currently, although a host of non-platinum candidate materials for HER were studied, the metallic platinum $(\mathrm{Pt})$ is still considered as "the Holy Grail" of HER electrocatalyst in acidic media with a nearly-zero onset overpotential and fast kinetics owing to its favorable hydrogen binding energy ${ }^{13,14}$. However, the natural scarcity, high cost and poor durability limit its large-scale commercial applications of water electrolyzers ${ }^{15,16}$. As a consequence, it is necessary to improve the intrinsically catalytic ability and the utilization efficiency of Pt for HER.

Hitherto, numerous efforts have been made to design Pt-based HER catalysts in acid ${ }^{17-24}$. For example, the catalytic efficiency of Pt metal could be boosted by the size ${ }^{17}$, composition ${ }^{18}$, morphology ${ }^{19}$, and crystal phase-engineering strategies ${ }^{20}$. Besides, hybridizing $\mathrm{Pt}$ with another component is also an effective way to achieve high-performance HER electrocatalysts via hydrogen spillover phenomenon ${ }^{21-24}$. Recently, hydrogen spillover opens new opportunities for improving the HER activity of binary metal/support catalysts with hydrogen-enriched $\mathrm{Pt}$ nanocrystals and hydrogen-deficient components, such as $\mathrm{WO}_{3-\mathrm{x}}{ }^{21}, \mathrm{SiO}_{2}{ }^{22}, \mathrm{RuCeO}_{\mathrm{x}}{ }^{23}, \mathrm{CoP}^{24}$. As schematically illustrated in Fig. 1a, hydrogen spillover-based binary-component catalyst (HSBCC) involves three main steps: (1) the strong proton $\left(\mathrm{H}^{+}\right)$ adsorption on metals (e.g., Pt with $\Delta G_{\mathrm{H}-\text { metal }}<0$ ), (2) the interfacial $\mathrm{H}$ diffusion and spillover from metals to supports, and (3) ccelerated exhaustion of fossil fuels accompanied with

efficient $\mathrm{H}_{2}$ desorption on supports $\left(\Delta G_{\mathrm{H} \text {-support }}>0\right)^{24}$. Nonetheless, considerable barriers need to be overcome for the hydrogen spillover process in HSBCC systems due to long reaction path and undesirable interfacial resistance within two components (e.g., Schottky barrier and unmatched lattice space $)^{2,25-27}$. Furthermore, HSBCCs always suffer from complicated synthesis processes, which are disadvantageous for costeffective and large-scale fabrication. In light of the short reaction path and interface-free feature in single-component catalysts $2,25,28,29$, the creation of atomic-level multiple catalytic sites for strong $\mathrm{H}^{+}$adsorption, thermo-neutral $\mathrm{H}$ adsorption and facile $\mathrm{H}_{2}$ desorption simultaneously in hydrogen spillover-based single-component catalyst (HSSCC) system (as illustrated in Fig. 1b), is highly desirable to boost the acidic HER activity; yet still, such single-phase catalysts have not been reported so far.

Multi-metal oxides have attracted great interest in many catalytic applications by virtue of their structural and compositional flexibility ${ }^{30-32}$. The multiple elements and variable crystal structures could endow multi-metal oxides with some unique geometrical and electronic properties, consequently tailoring the binding behavior of reaction intermediates and promoting their electrocatalytic activities ${ }^{30-32}$. Inspired by aforementioned considerations, here we demonstrate a unique family of complex metal oxide prepared by a facile solid-phase reaction method, $\mathrm{La}_{2} \mathrm{Sr}_{2} \mathrm{PtO}_{7+\delta}$, as a highly active and durable HER electrocatalyst in acid media. This complex oxide crystallizes in a hexagonal structure with alternating layers of $\left[\mathrm{La}_{2} \mathrm{PtO}_{6}\right]$ containing isolated $\mathrm{Pt}^{\mathrm{IV}} \mathrm{O}_{6}$ octahedra and $\left[\mathrm{Sr}_{2} \mathrm{O}_{1+\delta}\right]$ slabs. The $\mathrm{La}_{2} \mathrm{Sr}_{2} \mathrm{PtO}_{7+\delta}$ oxide displays a remarkable HER activity with a low overpotential of $13 \mathrm{mV}$ at $10 \mathrm{~mA} \mathrm{~cm}^{-2}$ and a small Tafel slope of $22 \mathrm{mV} \mathrm{dec}^{-1}$ in $0.5 \mathrm{M} \mathrm{H}_{2} \mathrm{SO}_{4}$, superior to state-of-the-art HSBCCs and other Ptbased catalysts ever reported. In addition, the $\mathrm{La}_{2} \mathrm{Sr}_{2} \mathrm{PtO}_{7+\delta}$ shows significant enhancement in the intrinsic activity and operational durability as compared with the commercial Pt black catalyst. Comprehensive experiments and electrochemical measurements were performed to support the possible occurrence of hydrogen spillover in $\mathrm{La}_{2} \mathrm{Sr}_{2} \mathrm{PtO}_{7+\delta}$. First-principles calculations suggest that the hydrogen adsorption at La-Pt bridge site in $\mathrm{La}_{2} \mathrm{Sr}_{2} \mathrm{PtO}_{7+\delta}$ is nearly thermo-neutral, which could serve as the mediators for favorable hydrogen spillover and accordingly result in exceptionally high activity. Specifically, a unique synergistic mechanism of multi-function catalytic sites in $\mathrm{La}_{2} \mathrm{Sr}_{2} \mathrm{PtO}_{7+\delta}$ involving hydrogen spillover for HER was proposed: the $\mathrm{O}$ site serves as the proton enrichment, the thermo-neutral La-Pt bridge

b

a Long pathway
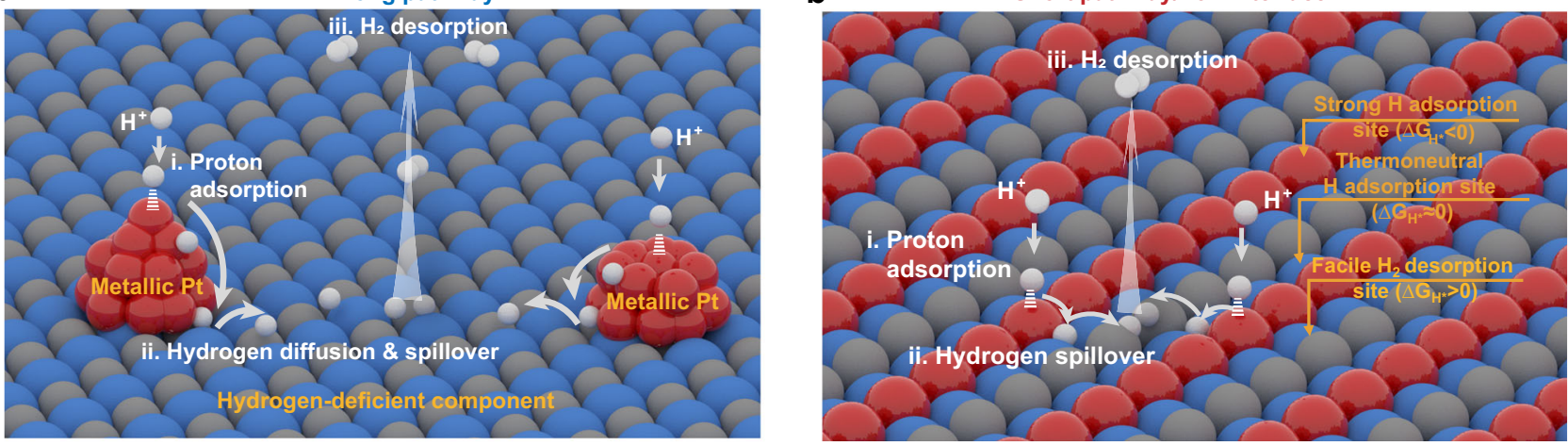

Hydrogen spillover-based single-component catalyst (HSSCC)

Fig. 1 Schematic illustration of the hydrogen spillover on two-type catalyst systems for HER in acidic media. a The conventional hydrogen spilloverbased binary-component catalyst (HSBCC) system by coupling hydrogen-enriched Pt-based nanocrystals with hydrogen-deficient component. Red balls represent Pt atoms and blue and gray balls represent compounds. b Hydrogen spillover-based single-component catalyst (HSSCC) system with atomiclevel multiple catalytic sites. Red, blue and gray balls represent strong $\mathrm{H}$ adsorption, thermoneutral $\mathrm{H}$ adsorption and facile $\mathrm{H}_{2}$ desorption sites, respectively. 
a

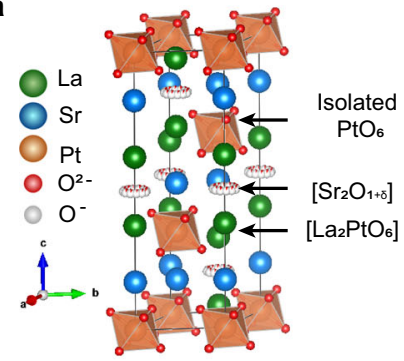

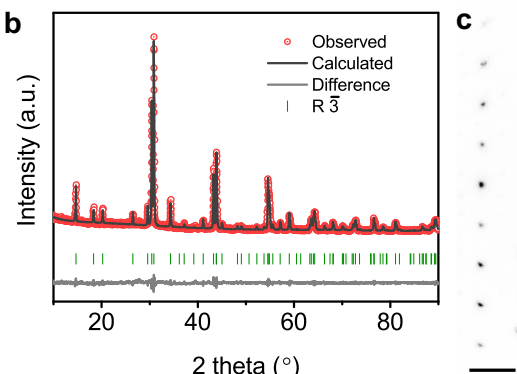
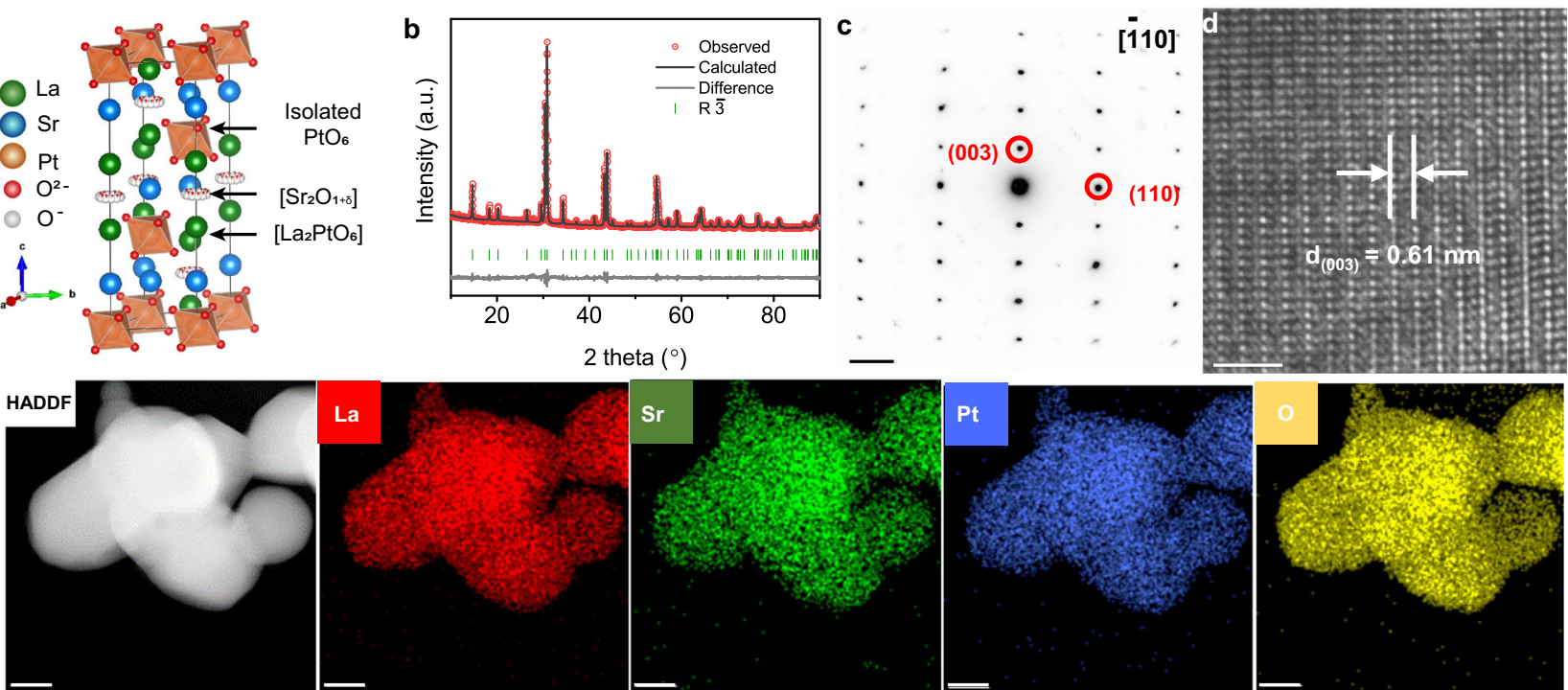

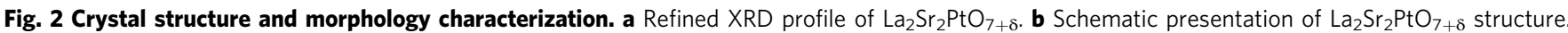
c SAED pattern along the [-110] direction and $\mathbf{d}$ the corresponding HRTEM image of $\mathrm{La}_{2} \mathrm{Sr}_{2} \mathrm{PtO}_{7+\delta}$. e HAADF-STEM and the corresponding elemental mapping images of $\mathrm{La}_{2} \mathrm{Sr}_{2} \mathrm{PtO}_{7+\delta}$. Scale bar in $\mathbf{c}$ is $2 \mathrm{~nm}^{-1}$, in $\mathbf{d}$ is $2 \mathrm{~nm}$ and in e is $100 \mathrm{~nm}$.

site serves as the mediator for favorable hydrogen spillover/ migration from $\mathrm{O}$ site to $\mathrm{Pt}$ site, and $\mathrm{Pt}$ site favors the final $\mathrm{H}_{2}$ desorption. This work opens a new avenue for the design of highperformance HER catalysts in acid media though hydrogen spillover among multi-function-site synergy in single component.

\section{Results}

Crystal structure and morphology. The kind of complex oxide $\mathrm{La}_{2} \mathrm{Sr}_{2} \mathrm{PtO}_{7+\delta}$ crystallizes in a hexagonal structure containing oxidized $\mathrm{Pt}$ ion as the $\mathrm{B}$-site cation. Actually, $\mathrm{La}_{2} \mathrm{Sr}_{2} \mathrm{PtO}_{7+\delta}$ is the $n=2$ member of the general family of $\left[\mathrm{A}_{2}^{\prime} \mathrm{O}_{1+\delta}\right]\left[\mathrm{A}_{n} \mathrm{~B}_{\mathrm{n}-1} \mathrm{O}_{3 n}\right]$ hexagonal perovskites with $n$ representing the number of $\mathrm{AO}_{3}$ successive layers ${ }^{33}$. Along the $c$-axis, the structure of $\mathrm{La}_{2} \mathrm{Sr}_{2} \mathrm{PtO}_{7+\delta}$ can be presented by the uniform stacking of two $\mathrm{LaO}_{3}$ layers and one $\mathrm{Sr}_{2} \mathrm{O}_{1+\delta}$ layer (Fig. $2 \mathrm{a}$ ). In the $\left[\mathrm{La}_{2} \mathrm{PtO}_{6}\right]$ slab, the $\mathrm{Pt}$ ions occupy the octahedral sites between the neighboring $\mathrm{LaO}_{3}$ layers to form isolated $\mathrm{PtO}_{6}$ units. The $\mathrm{La}_{2} \mathrm{Sr}_{2} \mathrm{PtO}_{7+\delta}$ oxide powder were successfully prepared by conventional solid-state synthesis, and the crystal structure was initially verified by X-ray diffraction (XRD). Rietveld refinement of the XRD pattern reveals that the $\mathrm{La}_{2} \mathrm{Sr}_{2} \mathrm{PtO}_{7+\delta}$ adopts a hexagonal structure with a space group of R-3, and lattice parameters of $a=b=5.7913(2) \AA$, $c=18.1097(7) \AA$ (Fig. 2b and Supplementary Table 1), which well agrees with previous study ${ }^{33}$. The phase structure was further confirmed by the selected area electron diffraction (SAED) pattern along the $[-110]$ direction and the corresponding highresolution transmission electron microscopy (HRTEM) image. The SAED pattern in Fig. $2 c$ reflects the hexagonally arranged diffraction spots of $[-110]$ zone axis. A lattice fringe with lattice spacing of $0.61 \mathrm{~nm}$ was seen in the HRTEM image (Fig. 2d), corresponding to the (003) plane of $\mathrm{La}_{2} \mathrm{Sr}_{2} \mathrm{PtO}_{7+\delta}$ oxide. Besides, the morphology of $\mathrm{La}_{2} \mathrm{Sr}_{2} \mathrm{PtO}_{7+\delta}$ powder was examined by scanning electron microscopy (SEM). Some chunks composed of micrometer-sized particles were observed (Supplementary Fig. 1), suggesting the bulk nature of the as-synthesized $\mathrm{La}_{2} \mathrm{Sr}_{2} \mathrm{PtO}_{7+\delta}$ oxide by solid-state reaction method. As shown in Fig. 2e, the high-angle annular dark-field scanning transmission electron microscopy and elemental mapping images demonstrate the homogeneous distribution of all elements in the as-prepared $\mathrm{La}_{2} \mathrm{Sr}_{2} \mathrm{PtO}_{7+\delta}$ material. For a direct comparison in this work, commercial Pt black catalyst was also included and the pure phase structure was confirmed by XRD patterns (Supplementary Fig. 2). The Pt black catalyst has broad XRD peaks, implying nanocrystalline feature of the metallic $\mathrm{Pt}$ as evidenced by small nanoparticles $(\sim 5 \mathrm{~nm})$ in TEM image (Supplementary Fig. 3).

Electronic structure. X-ray photoelectron spectroscopy (XPS) and X-ray absorption spectroscopy (XAS) were carried out to explore the surface chemical state and electronic structure of $\mathrm{La}_{2} \mathrm{Sr}_{2} \mathrm{PtO}_{7+\delta}$. Supplementary Fig. 4 presents the full XPS spectrum of $\mathrm{La}_{2} \mathrm{Sr}_{2} \mathrm{PtO}_{7+\delta}$, which demonstrates the existence of $\mathrm{La}, \mathrm{Sr}$, $\mathrm{Pt}$, and $\mathrm{O}$ elements on the surface. As seen from the highresolution Pt $4 f$ core level spectra in Fig. 3a, two peaks at 74.9 and $78.1 \mathrm{eV}$ were observed, which could be ascribed to the Pt $4 f_{7 / 2}$ and Pt $4 f_{5 / 2}$ orbitals of oxidized Pt (IV) species ${ }^{13,23,34}$. Notably, in contrast to the Pt $4 f$ spectra of commercial Pt black, no signals from metallic Pt at 71.4 and $74.7 \mathrm{eV}$ were detected, indicating the absence of metallic $\mathrm{Pt}$ in the $\mathrm{La}_{2} \mathrm{Sr}_{2} \mathrm{PtO}_{7+\delta}$. To further confirm the oxidation state of Pt ions in $\mathrm{La}_{2} \mathrm{Sr}_{2} \mathrm{PtO}_{7+\delta}$, X-ray absorption nearedge structure (XANES) spectra were also collected along with standard Pt foil as a reference (Fig. 3b). XANES spectrum at the $5 d L_{3}$-edge is highly sensitive to the valence state of $5 d$ elements: an increase of the valence state of the $5 d$ metal ion by one causes a shift of the $L_{3}$ spectra by more than one $\mathrm{eV}$ toward higher energies $^{35,36}$. The intensity of white line peak in Pt $L_{3}$-edge XANES spectra associates with the electronic transition from $2 p_{3 / 2}$ to unoccupied $5 d$ states and discloses the oxidation state of $\mathrm{Pt}$ species ${ }^{16,17}$. The white-line intensity of the $\mathrm{La}_{2} \mathrm{Sr}_{2} \mathrm{PtO}_{7+\delta}$ is much higher than that of the metallic $\mathrm{Pt}$ foil, suggesting $\mathrm{Pt}$ oxide species in $\mathrm{La}_{2} \mathrm{Sr}_{2} \mathrm{PtO}_{7+\delta} 16,17$. Moreover, the white line of $\mathrm{Pt}-L_{3}$ of $\mathrm{La}_{2} \mathrm{Sr}_{2} \mathrm{PtO}_{7+\delta}$ locates at about $1.5 \mathrm{eV}$ higher in energy than that of $\mathrm{Pt}$ foil indicating further higher oxidation state of the former. It is also well known that the extended X-ray absorption fine structure (EXAFS) is sensitive tool to uncover the local coordination of $5 \mathrm{~d}$ elements ${ }^{37,38}$. Figure $3 \mathrm{c}$ shows the $k^{3}$-weighted Fourier transform (FT) curves at R space of Pt $L_{3}$-edge EXAFS spectra for $\mathrm{La}_{2} \mathrm{Sr}_{2} \mathrm{PtO}_{7+\delta}$ in comparison with the Pt foil reference. The most intense peak at $1.64 \AA$ for $\mathrm{La}_{2} \mathrm{Sr}_{2} \mathrm{PtO}_{7+\delta}$ was detected, corresponding to Pt-O bond ${ }^{17,39}$. Also, the isolated $\mathrm{PtO}_{6}$ octahedra in $\mathrm{La}_{2} \mathrm{Sr}_{2} \mathrm{PtO}_{7+\delta}$ is evidenced by the absence of the Pt-Pt coordination at $\sim 2.52 \AA$ in the first-shell region relative to $\mathrm{Pt}$ foil ${ }^{17,40}$. To visually explore the coordination conditions of $\mathrm{Pt}$, a more powerful wavelet transform (WT) analysis was 
a
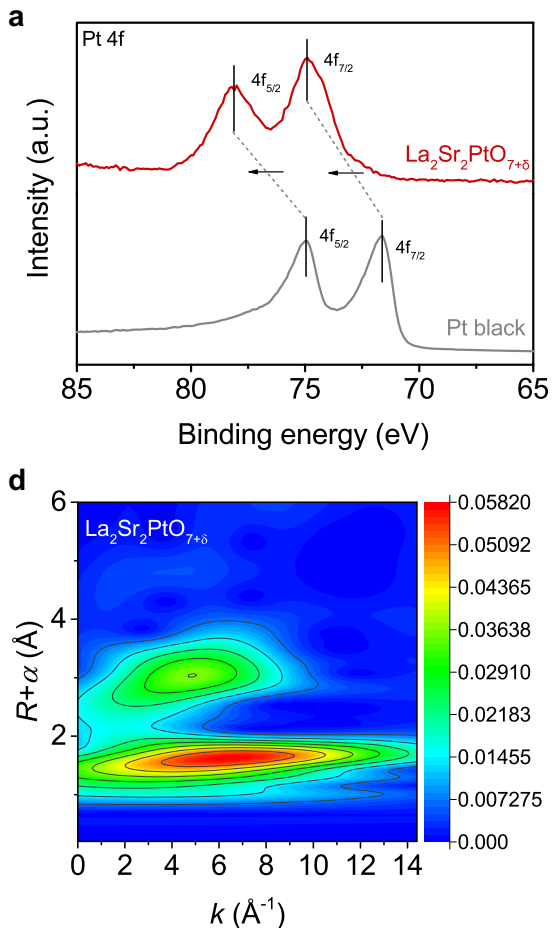
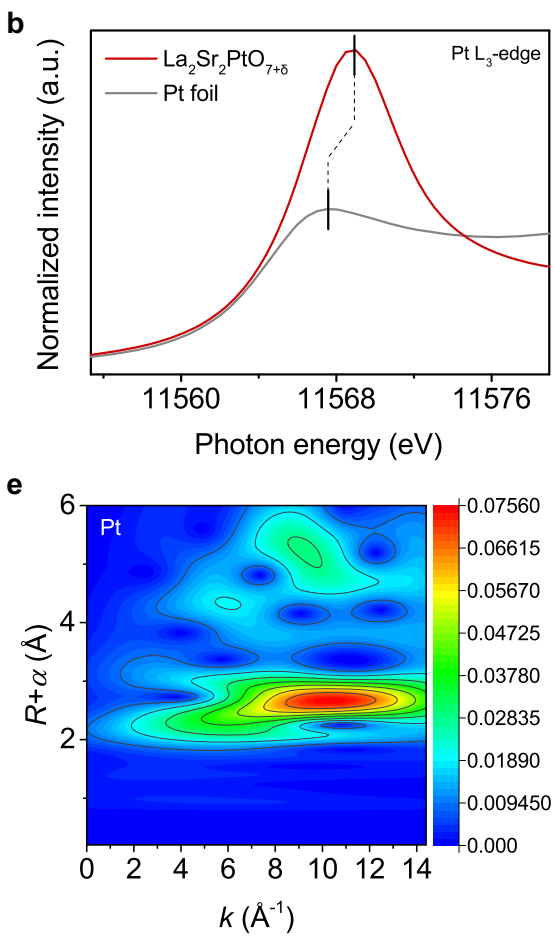

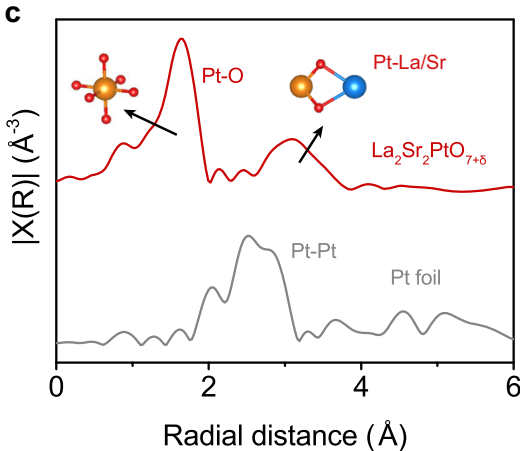

f

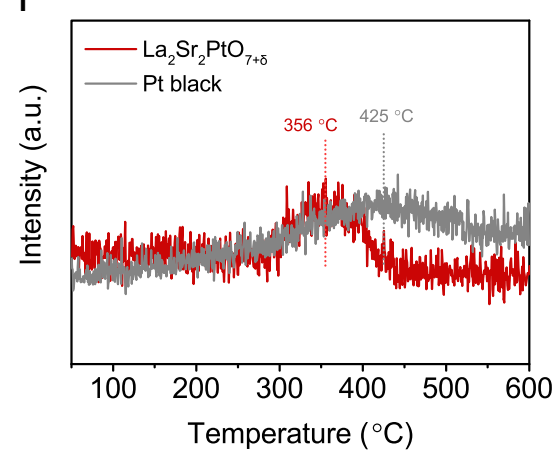

Fig. 3 Electronic structure characterization. a The high-resolution Pt $4 f$ XPS spectra of $\mathrm{La}_{2} \mathrm{Sr}_{2} \mathrm{PtO}_{7+\delta}$ and Pt black. b Pt $L_{3}$-edge $X A N E S$ spectra and $\mathbf{c} K^{3}$. weighted Fourier transform EXAFS spectra of the $\mathrm{La}_{2} \mathrm{Sr}_{2} \mathrm{PtO}_{7+\delta}$ and Pt foil. Wavelet transform for the $\mathrm{K}^{3}-$ weighted EXAFS spectra of $\mathbf{d} \mathrm{La}_{2} \mathrm{Sr}_{2} \mathrm{PtO}_{7+\delta}$ and e Pt foil. $\mathbf{f} \mathrm{H}_{2}$-TPD profiles of $\mathrm{La}_{2} \mathrm{Sr}_{2} \mathrm{PtO}_{7+\delta}$ and Pt black.

performed to directly reflect the structure information in the resolution of $\mathrm{R}$ space and $\mathrm{k}$ space. As shown in Fig. 3d, The WT intensity maximum of $\mathrm{La}_{2} \mathrm{Sr}_{2} \mathrm{PtO}_{7+\delta}$ occurs near $\mathrm{R}$ space of $1.7 \AA$ and $\mathrm{k}$ space of $6.5 \AA^{-1}$, confirming the coordination structure of Pt$\mathrm{O}$ bonds in the first coordination shell. As for Pt foil, a new WT intensity maximum near $2.7 \AA$ and $10.4 \AA^{-1}$ appears in Fig. 3e, which is associated with Pt-Pt bonding. Based on previous studies, the $5 d$ orbital of the Pt sites in a highly oxidized state can hybridize with the $\mathrm{H} 1 s$ orbital to form weak $\mathrm{Pt}-\mathrm{H}$ bonds, giving rise to enhanced intrinsic activity and facile $\mathrm{H}_{2}$ evolution ${ }^{13,41}$. Accordingly, the unique electronic structure of oxidized $\mathrm{Pt}$ sites in $\mathrm{La}_{2} \mathrm{Sr}_{2} \mathrm{PtO}_{7+\delta}$ is expected to help tailor the hydrogen binding energy on the catalyst surface and thereby improve the catalytic activity. Hydrogen temperature-programmed desorption $\left(\mathrm{H}_{2}-\mathrm{TPD}\right)$ measurements were carried out to investigate the $\mathrm{Pt}-\mathrm{H}$ binding capability of $\mathrm{La}_{2} \mathrm{Sr}_{2} \mathrm{PtO}_{7+\delta}$ and $\mathrm{Pt}$ black ${ }^{42,43}$. In Fig. 3f, the $\mathrm{H}_{2}$ desorption process of Pt black occurs within the temperature window of $276-558^{\circ} \mathrm{C}$ with a peak at $425^{\circ} \mathrm{C}$. The $\mathrm{La}_{2} \mathrm{Sr}_{2} \mathrm{PtO}_{7+\delta}$ shows lower desorption peak temperature of $356^{\circ} \mathrm{C}$, indicative of the weakened hydrogen binding energy and easier $\mathrm{H}_{2}$ desorption. Combining above analysis, the $\mathrm{Pt}$ in $\mathrm{La}_{2} \mathrm{Sr}_{2} \mathrm{PtO}_{7+\delta}$ is in an oxidized state $\left(\sim \mathrm{Pt}^{4+}\right)$, which is beneficial for $\mathrm{H}_{2}$ desorption.

Electrocatalytic HER performance in acid. To evaluate the acidic HER electrocatalytic performance of $\mathrm{La}_{2} \mathrm{Sr}_{2} \mathrm{PtO}_{7+\delta}$, we conducted electrochemical measurements in $0.5 \mathrm{M} \mathrm{H}_{2} \mathrm{SO}_{4}$ solution using a standard three-electrode configuration. The commercial Pt black was also tested under identical conditions for comparison. If not specified otherwise, all potentials in this work were $i R$-corrected to remove the ohmic drop across the electrolyte and referenced to a reversible hydrogen electrode (RHE, see Supplementary Fig. 5 for calibration). As seen from the polarization curves in Fig. 4a, the $\mathrm{La}_{2} \mathrm{Sr}_{2} \mathrm{PtO}_{7+\delta}$ exhibits a very small overpotential of $13 \mathrm{mV}$ at a current density of $-10 \mathrm{~mA} \mathrm{~cm}{ }^{-2}$, close to that $(3 \mathrm{mV})$ of commercial Pt black catalyst. The HER activity of $\mathrm{La}_{2} \mathrm{Sr}_{2} \mathrm{PtO}_{7+\delta}$ was also assessed in $\mathrm{H}_{2}$-saturated $0.5 \mathrm{M} \mathrm{H}_{2} \mathrm{SO}_{4}$ to ensure the $\mathrm{H}_{2} / \mathrm{H}_{2} \mathrm{O}$ equilibrium for HER (Supplementary Fig. 6), which presents the superior HER activity $\left(\eta_{10}\right.$ of $27 \mathrm{mV}$ and Tafel slope of $19 \mathrm{mV} \mathrm{dec}^{-1}$ ) among the state-of-the-art HER electrocatalysts (Supplementary Table 2). Besides, the stoichiometric $\mathrm{La}_{2} \mathrm{Sr}_{2} \mathrm{PtO}_{7+\delta}$ oxide shows higher HER activity than other non-stoichiometric complex oxides (Supplementary Fig. 7), indicating that $\mathrm{La}_{2} \mathrm{Sr}_{2} \mathrm{PtO}_{7+\delta}$ with stoichiometric element composition is the optimized catalyst for HER. To examine the kinetics and reaction mechanism, Tafel plots were drawn in Fig. 4b. The Tafel slope for $\mathrm{La}_{2} \mathrm{Sr}_{2} \mathrm{PtO}_{7+\delta}(22 \mathrm{mV} \mathrm{dec}-1)$ is smaller than that for Pt black $\left(30 \mathrm{mV} \mathrm{dec}^{-1}\right)$, implying faster HER rates. Noticeably, such a small Tafel slop value of $22 \mathrm{mV} \mathrm{dec}{ }^{-1}$ for $\mathrm{La}_{2} \mathrm{Sr}_{2} \mathrm{PtO}_{7+\delta}$ suggests that the acidic HER electrocatalysis of the $\mathrm{La}_{2} \mathrm{Sr}_{2} \mathrm{PtO}_{7+\delta}$ catalyst may follow a different reaction mechanism to conventional Volmer-Tafel, as will be discussed below. Above electrochemical analyses (e.g., small overpotential and low Tafel slope) highlight the extraordinary electrode activity of $\mathrm{La}_{2} \mathrm{Sr}_{2} \mathrm{PtO}_{7+\delta}$ for $\mathrm{HER}$ in acidic media, although $\mathrm{La}_{2} \mathrm{Sr}_{2} \mathrm{PtO}_{7+\delta}$ is one bulk material composed of micrometer-sized particles. Such excellent HER activity of $\mathrm{La}_{2} \mathrm{Sr}_{2} \mathrm{PtO}_{7+\delta}$ is superior to that of reported HSBCCs and state-ofthe-art Pt-based catalysts up to now (Fig. 4c and Supplementary Table 3), demonstrating that $\mathrm{La}_{2} \mathrm{Sr}_{2} \mathrm{PtO}_{7+\delta}$ ranks the top HER electrocatalyst in acidic media. It's known that two aspects (i.e., the intrinsic activity of each active site and the number of active sites) generally determine the overall catalytic activity of electrocatalysts ${ }^{44}$. To assess the intrinsic activity of $\mathrm{La}_{2} \mathrm{Sr}_{2} \mathrm{PtO}_{7+\delta}$, we further calculated the specific activity by normalizing the electrode activity to the electrochemical surface area (ECSA) and real surface area (RSA). The values of ECSA and RAS of catalysts were estimated from the hydrogen underpotential deposition $\left(\mathrm{H}_{\mathrm{UPD}}\right)$ (Supplementary Fig. 8) and Brunner-Emmet-Teller measurements (Supplementary Fig. 9). Notably, the ECSA values of $\mathrm{La}_{2} \mathrm{Sr}_{2} \mathrm{PtO}_{7+\delta}$ and $\mathrm{Pt}$ black were determined by integrating the charge of $\mathrm{H}_{\mathrm{UPD}}$ desorption peak in cyclic voltammogram (CV) 


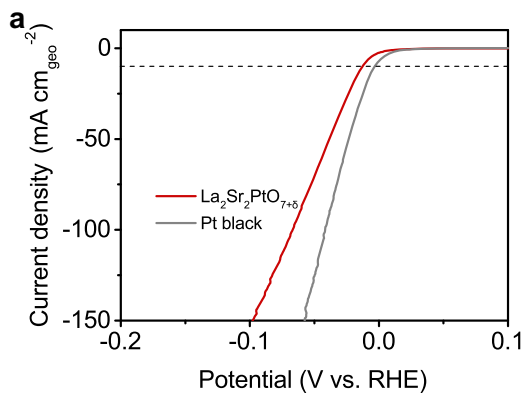

d
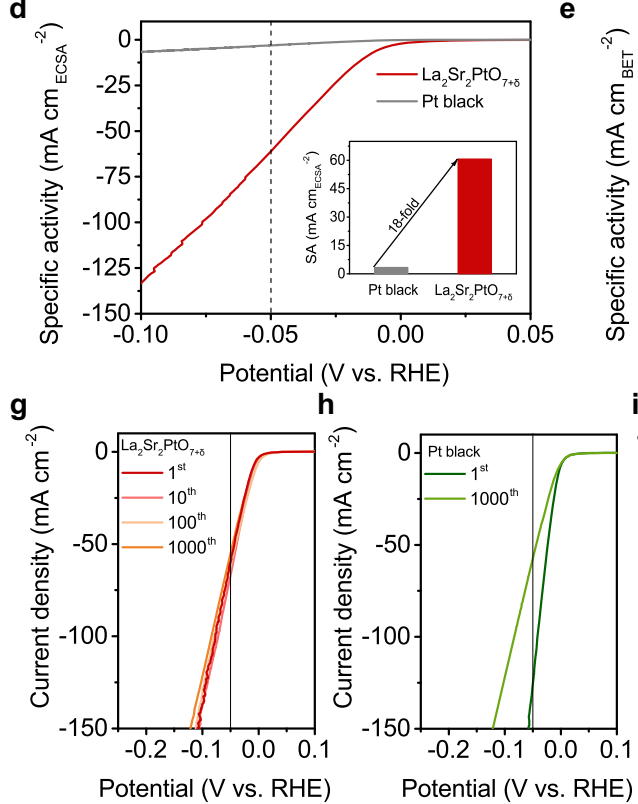
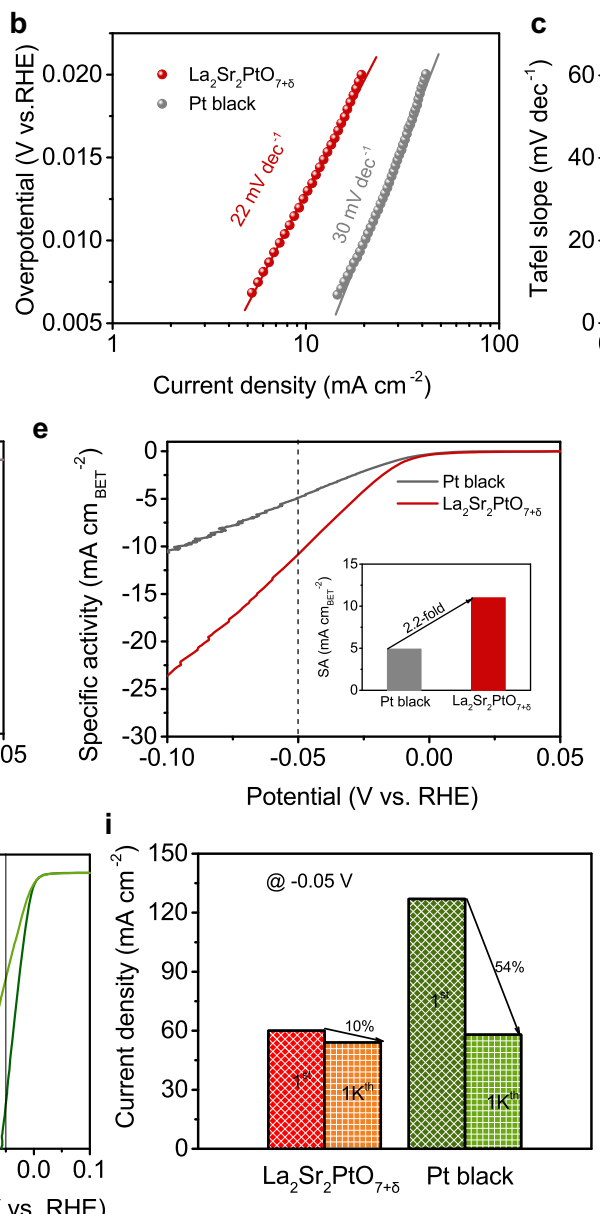

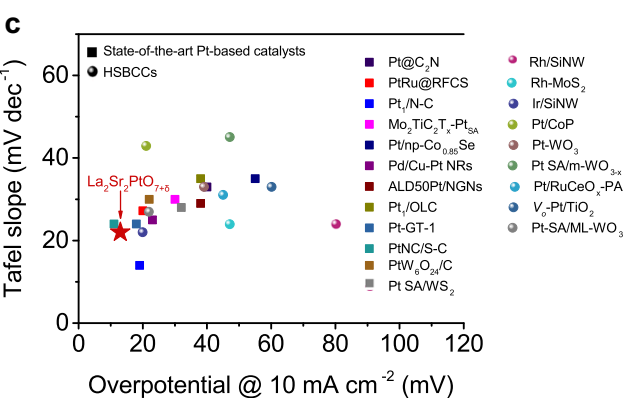

f

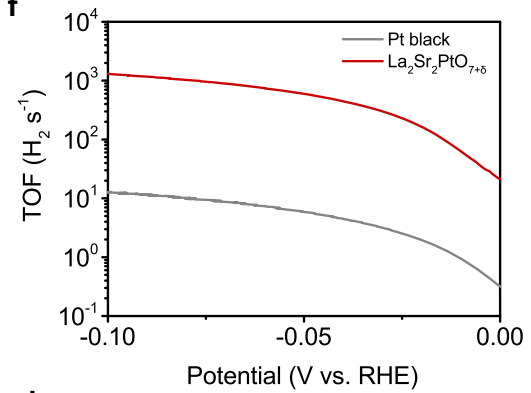

j

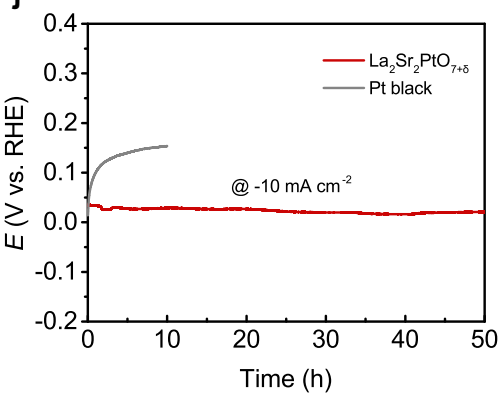

Fig. 4 Electrocatalytic HER performance in acid. a Polarization curves of $\mathrm{La}_{2} \mathrm{Sr}_{2} \mathrm{PtO}_{7+\delta}$ and Pt black in an Ar-saturated $0.5 \mathrm{M} \mathrm{H}_{2} \mathrm{SO}_{4}$ solution with a scan rate of $5 \mathrm{mV} \mathrm{s}^{-1}$. b Tafel plots of $\mathrm{La}_{2} \mathrm{Sr}_{2} \mathrm{PtO}_{7+\delta}$ and Pt black. $\mathbf{c}$ HER activity comparison between $\mathrm{La}_{2} \mathrm{Sr}_{2} \mathrm{PtO}_{7+\delta}$ and HSBCCs and other state-of-the-art Ptbased catalysts ever reported. Specific activity normalized to $\mathbf{d}$ ECSA and e RSA of $\mathrm{La}_{2} \mathrm{Sr}_{2} \mathrm{PtO}_{7+\delta}$ and Pt black as a function of applied potential. Inset:

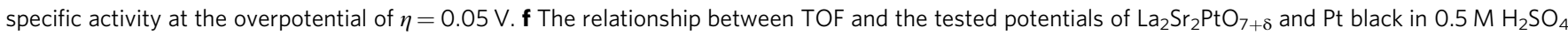
solution. $\mathbf{g}$ Polarization curves of $\mathrm{La}_{2} \mathrm{Sr}_{2} \mathrm{PtO}_{7+\delta}$ initially, as well as after 10, 100, and 1000 cycles. h Polarization curves of Pt black initially and after 1000 cycles. i Current density comparison at $-0.05 \mathrm{~V}$ vs. RHE initially and after 1000 cycles for $\mathrm{La}_{2} \mathrm{Sr}_{2} \mathrm{PtO}_{7+\delta}$ and Pt black. $\mathbf{j}$ Chronopotentiometry response of $\mathrm{La}_{2} \mathrm{Sr}_{2} \mathrm{PtO}_{7+\delta}$ and Pt black at a constant cathodic current density of $10 \mathrm{~mA} \mathrm{~cm}{ }^{-2}$.

curves according to previous studies ${ }^{45,46}$. As we can see in Supplementary Fig. 8, the $\mathrm{H}_{\mathrm{UPD}}$ integrated area of $\mathrm{La}_{2} \mathrm{Sr}_{2} \mathrm{PtO}_{7+\delta}$ $\left(1.99 \mathrm{~m}^{2} / \mathrm{g}_{\mathrm{Pt}}\right)$ is obviously smaller than that $\left(70.11 \mathrm{~m}^{2} / \mathrm{g}_{\mathrm{Pt}}\right.$, similar with previous studies ${ }^{45,46}$ ) of Pt black, which may stem from the low oxide surface area $\left(2.8 \mathrm{~m}^{2} \mathrm{~g}^{-1}\right)$ and bulk morphology of $\mathrm{La}_{2} \mathrm{Sr}_{2} \mathrm{PtO}_{7+\delta}$. Surprisingly, regardless of the electrode activity normalized to the ECSA or RSA, the $\mathrm{La}_{2} \mathrm{Sr}_{2} \mathrm{PtO}_{7+\delta}$ catalyst offers a much higher specific activity than Pt black (Fig. 4d, e). For instance, at $\eta=0.05 \mathrm{~V}$, the enhancement values in specific activity normalized to the ECSA and RSA for $\mathrm{La}_{2} \mathrm{Sr}_{2} \mathrm{PtO}_{7+\delta}$ are up to about 18 and 2.2 times as compared with Pt black, indicative of its superior intrinsic activity toward acidic HER. Moreover, turnover frequency (TOF) values of $\mathrm{La}_{2} \mathrm{Sr}_{2} \mathrm{PtO}_{7+\delta}$ and Pt black were calculated to further compare their intrinsic activity, which represents the amount of $\mathrm{H}_{2}$ molecule evolving per active site per second. TOF was plotted vs. potential (Fig. $4 \mathrm{f}$ ) based on the calculated numbers of surface active sites according to the previouslyreported methods (see Supplementary Fig. 10 and Supplementary Note. 1 $)^{47,48}$. Remarkably, the $\mathrm{La}_{2} \mathrm{Sr}_{2} \mathrm{PtO}_{7+\delta}$ delivers an high TOF value of $596 \mathrm{~s}^{-1}$ at overpotential of $0.05 \mathrm{~V}$, which is about two orders of magnitude higher than the commercial Pt black. Although $\mathrm{La}_{2} \mathrm{Sr}_{2} \mathrm{PtO}_{7+\delta}$ possesses higher intrinsic activity than commercial Pt black, its mass activity is inferior to Pt black due to lower surface area (Supplementary Fig. 11); future ongoing investigation could shed more light on improving the surface area of $\mathrm{La}_{2} \mathrm{Sr}_{2} \mathrm{PtO}_{7+\delta}$. As a control sample, a well-known $\mathrm{Pt} / \mathrm{WO}_{3}$ HSBCC was also prepared for comparison (Supplementary Fig. 12a $)^{21}$. As seen from Supplementary Fig. 12b, the singlecomponent $\mathrm{La}_{2} \mathrm{Sr}_{2} \mathrm{PtO}_{7+\delta}$ shows much higher intrinsic activity than binary-component $\mathrm{Pt} / \mathrm{WO}_{3}$, confirming the superiority of the HSSCC system over the HSBCC system.

In addition to the catalytic activity, we also take the long-term durability of the $\mathrm{La}_{2} \mathrm{Sr}_{2} \mathrm{PtO}_{7+\delta}$ catalyst into consideration to assess its potential for practical application. For this purpose, the accelerated durability tests (ADT) by continuous cycling within HER potential window were conducted. As shown in Fig. 4g, after 1000-cycling, the $\mathrm{La}_{2} \mathrm{Sr}_{2} \mathrm{PtO}_{7+\delta}$ exhibits only slight activity decline but Pt black suffers from obvious activity loss. For example, $\mathrm{La}_{2} \mathrm{Sr}_{2} \mathrm{PtO}_{7+\delta}$ displays a decay of only $10 \%$ whereas a nearly 5.4-fold faster decay rate (54\%) was observed for Pt black during the period of continuous 1000-cycle operation (Fig. 4h, i). The poor stability of Pt black catalyst may be associated with the dissolution of $\mathrm{Pt}$ surface atoms and the agglomeration of $\mathrm{Pt}$ particles ${ }^{49-51}$. In conjunction with a series of post-HER measurements including XRD, XAS, TEM and STEM-EDS (Supplementary Fig. 13-16), some metallic Pt species are formed 
a

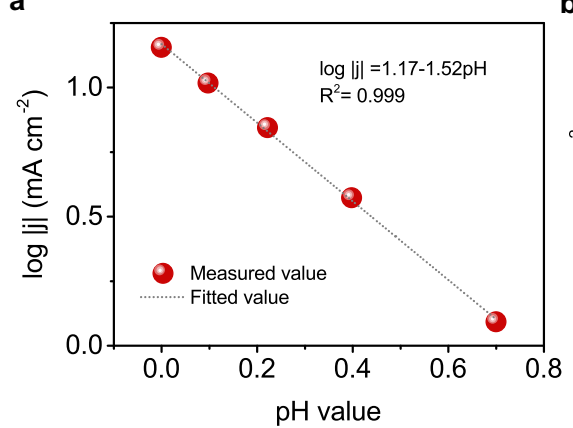

d

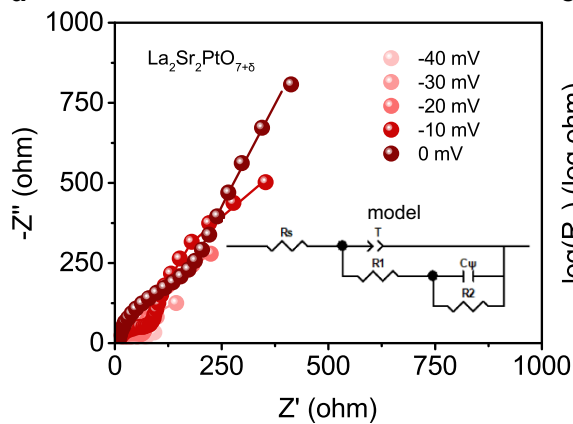

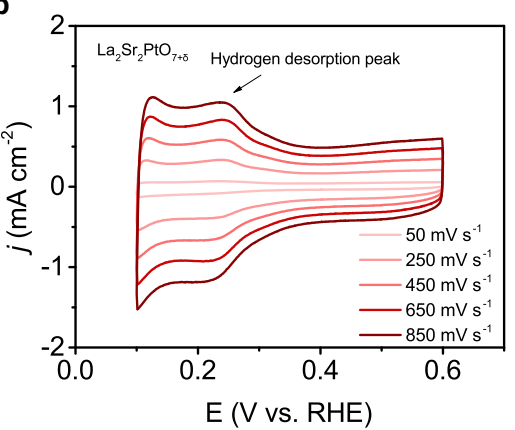

e

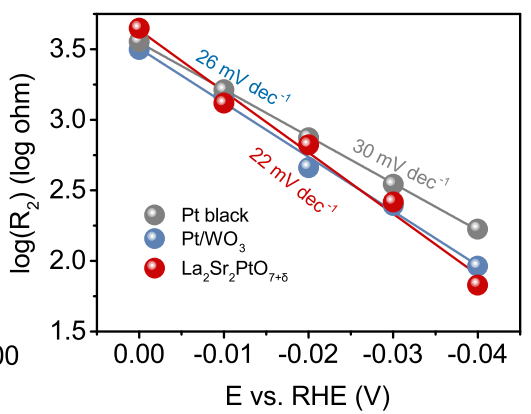

c

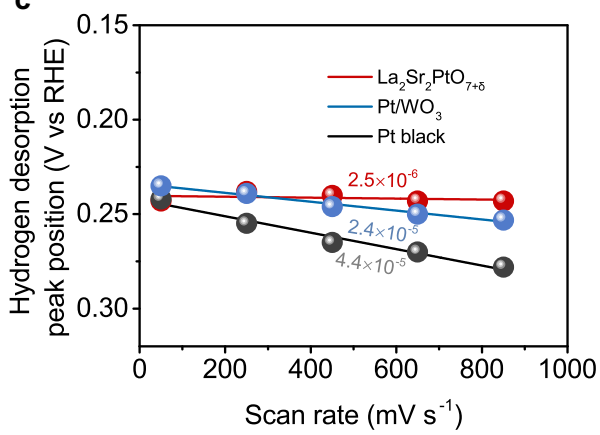

f

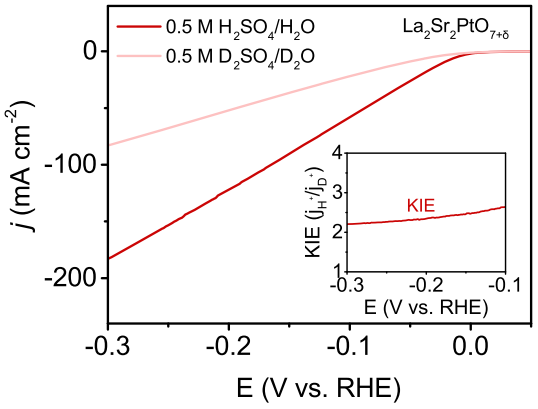

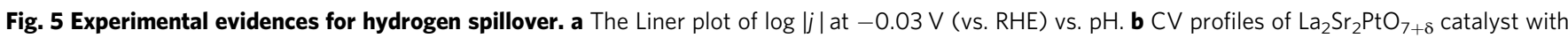
the scan rate from 50 to $850 \mathrm{mV} \mathrm{s}^{-1}$ in Ar-saturated $0.5 \mathrm{M} \mathrm{H}_{2} \mathrm{SO}_{4}$. c Plots of hydrogen desorption peak position vs. scan rates of the Pt black, Pt/WO 3 and $\mathrm{La}_{2} \mathrm{Sr}_{2} \mathrm{PtO}_{7+\delta}$ catalysts. d Nyquist plot for $\mathrm{La}_{2} \mathrm{Sr}_{2} \mathrm{PtO}_{7+\delta}$ catalyst at various HER overpotentials. The scattered symbol represents the experimental results, and the solid lines is simulated fitting results. The inset also shows the equivalent circuit for the simulation. e ElS-derived Tafel plots of the Pt black, Pt/ $\mathrm{WO}_{3}$ and $\mathrm{La}_{2} \mathrm{Sr}_{2} \mathrm{PtO}_{7+\delta}$ catalysts obtained from the hydrogen adsorption resistance $R_{2}$. f Polarization curves of $\mathrm{La}_{2} \mathrm{Sr}_{2} \mathrm{PtO}_{7+\delta}$ catalyst in aqueous $0.5 \mathrm{M}$ $\mathrm{H}_{2} \mathrm{SO}_{4}$ and $0.5 \mathrm{M} \mathrm{D}_{2} \mathrm{SO}_{4}$ solutions. The inset is the kinetic isotope effect value vs. potential.

on the surface, which may account for slight activity decline after 1000 -cycling due to inferior activity of metallic Pt than bulk $\mathrm{La}_{2} \mathrm{Sr}_{2} \mathrm{PtO}_{7+\delta}$ component. According to the linear fitting of XANES, the average Pt valence of $\mathrm{La}_{2} \mathrm{Sr}_{2} \mathrm{PtO}_{7+\delta}$ after HER is determined to be $\sim 3.4$ and thus the content of metallic Pt in postHER $\mathrm{La}_{2} \mathrm{Sr}_{2} \mathrm{PtO}_{7+\delta}$ is $\sim 15 \%$ (Supplementary Fig. 17). Besides, the SEM image showing in Supplementary Fig. 18 indicates the nearly unchanged morphology of $\mathrm{La}_{2} \mathrm{Sr}_{2} \mathrm{PtO}_{7+\delta}$ after HER. It should be noted that short-time cycling (e.g., 10-cycling) does not lead to the activity loss and $\mathrm{Pt}$ formation of $\mathrm{La}_{2} \mathrm{Sr}_{2} \mathrm{PtO}_{7+\delta}$, as reflect by almost overlapped polarization curve with the initial one and the absence of metallic Pt peak in XRD pattern after 10cycling. Besides, the negligible fluctuation of overpotential (@- $10 \mathrm{~mA} \mathrm{~cm}{ }^{-2}$ ) was observed for $\mathrm{La}_{2} \mathrm{Sr}_{2} \mathrm{PtO}_{7+\delta}$ during $50 \mathrm{~h}$ chronopotentiometry test (Fig. 4j), which further confirms the robust operation durability for HER. Overall, the high electrode/ intrinsic activity and electrochemical durability endow $\mathrm{La}_{2} \mathrm{Sr}_{2} \mathrm{PtO}_{7+\delta}$ as a promising HER electrocatalyst candidate for future practical application in acidic water electrolysis.

Experimental evidences for hydrogen spillover. In order to provide the evidences of possible atomic-scale hydrogen spillover in $\mathrm{La}_{2} \mathrm{Sr}_{2} \mathrm{PtO}_{7+\delta}$ for acidic HER electrocatalysis, comprehensive experiments and electrochemical measurements were performed. The hydrogen spillover could be initially confirmed by the color change in the mixture of the catalyst and $\mathrm{WO}_{3}{ }^{52}$. As seen from Supplementary Fig. 19, The $\mathrm{WO}_{3}$ after HER test exhibits an unchanged color. However, the mixture of $\mathrm{La}_{2} \mathrm{Sr}_{2} \mathrm{PtO}_{7+\delta}$ and $\mathrm{WO}_{3}$ after HER test generates a dark blue color, which is because that the spilled-over hydrogen migrates and readily reacts with $\mathrm{WO}_{3}$ to form dark blue $\mathrm{H}_{\mathrm{x}} \mathrm{WO}_{3}{ }^{52,53}$. Besides, the hydrogen spillover effect could be also verified by Tafel slope and $\mathrm{pH}$ - dependent HER experiments. The Tafel slope of $\mathrm{La}_{2} \mathrm{Sr}_{2} \mathrm{PtO}_{7+\delta}$ catalyst is only $22 \mathrm{mV} \mathrm{dec}^{-1}$, which is evidently lower than the value $\left(30 \mathrm{mV} \mathrm{dec}^{-1}\right)$ via conventional Volmer-Heyrovsky/Tafel mechanism, implying a hydrogen spillover-involving mechanism as also reported before ${ }^{54-56}$. This reaction mechanism was further supported by the $\mathrm{pH}$-dependent relation of HER (Supplementary Fig. 20 and Fig. 5a). The reaction order of 1.52 for the $\mathrm{La}_{2} \mathrm{Sr}_{2} \mathrm{PtO}_{7+\delta}$ catalyst is close to the theoretical value of 2 and similar with the reaction orders of the previously HSBCCs ${ }^{54-56}$.

In addition, referring to previous study, in situ analyzing the hydrogen adsorption and desorption kinetics on catalysts can support the occurrence of hydrogen spillover ${ }^{57}$. To examine the hydrogen desorption kinetics, the operando $\mathrm{CV}$ investigations were implemented and hydrogen desorption peaks during CV scanning in the double layer region were monitored ${ }^{21,58}$. For comparison, non-hydrogen-spillover metallic Pt black and wellknown $\mathrm{Pt} / \mathrm{WO}_{3}$ HSBCC samples were also studied. The $\mathrm{CV}$ curves of $\mathrm{Pt}$ black, $\mathrm{Pt} / \mathrm{WO}_{3}$ and $\mathrm{La}_{2} \mathrm{Sr}_{2} \mathrm{PtO}_{7+\delta}$ catalysts show the hydrogen desorption peak shift depending on the scan rate (Fig. 5b and Supplementary Fig. 21). Thus, it is rational to quantify their hydrogen desorption kinetics via plotting hydrogen desorption peak position vs. scan rate and comparing the fitted slopes. As shown in Fig. 5c, the slope follows the order of $\mathrm{Pt}$ black $>\mathrm{Pt} / \mathrm{WO}_{3}>\mathrm{La}_{2} \mathrm{Sr}_{2} \mathrm{PtO}_{7+\delta}$. The significantly reduced slope for $\mathrm{La}_{2} \mathrm{Sr}_{2} \mathrm{PtO}_{7+\delta}$ suggests its accelerated hydrogen desorption kinetics. It was reported that the hydrogen desorption kinetics for metal-support electrocatalysts could be effectively accelerated by hydrogen spillover effect ${ }^{21,57}$. Therefore, the fast kinetics of the hydrogen desorption for $\mathrm{La}_{2} \mathrm{Sr}_{2} \mathrm{PtO}_{7+\delta}$ could be originated from the efficient hydrogen spillover. The operando electrochemical impedance spectroscopy (EIS) investigations were further carried out on Pt black, $\mathrm{Pt} / \mathrm{WO}_{3}$ and $\mathrm{La}_{2} \mathrm{Sr}_{2} \mathrm{PtO}_{7+\delta}$ catalysts at different overpotentials to investigate the hydrogen adsorption kinetics. 
a

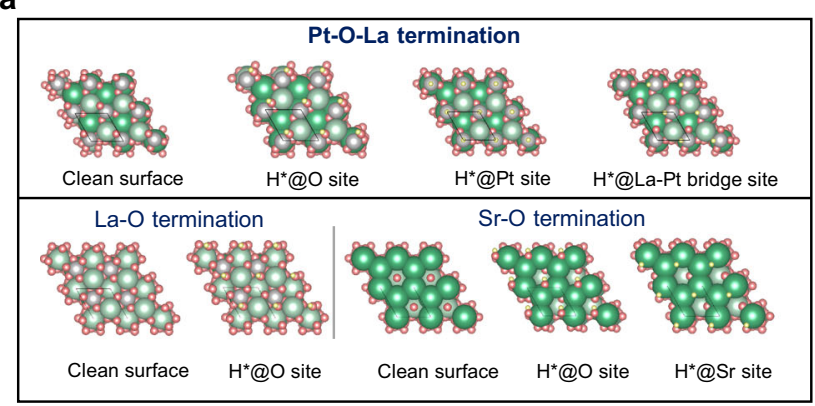

b

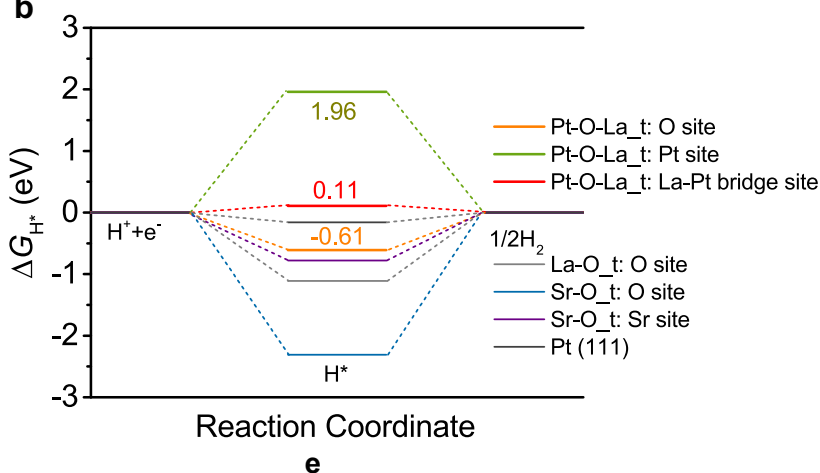

e

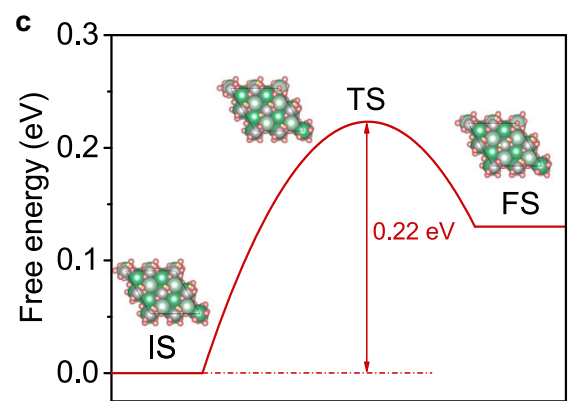

Reaction coordinate

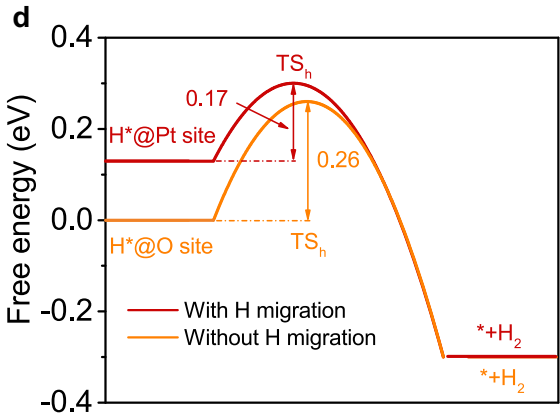

Reaction coordinate (i) $\mathrm{H}^{+}$adsorption (ii) $\mathrm{H}^{\star}$ migration (iii) $\mathrm{H}_{2}$ desorption

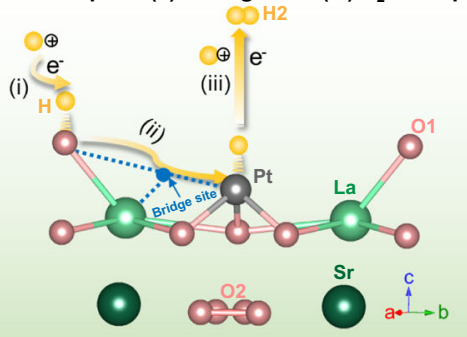

Fig. 6 DFT calculations. a (001) surface slab models with different terminations of $\mathrm{La}_{2} \mathrm{Sr}_{2} \mathrm{PtO}_{7+\delta}$ and the optimized structures. The yellow, red, gray, light and dark green balls represent $\mathrm{H}, \mathrm{O}, \mathrm{Pt}$, La and Sr, respectively. b Gibbs free energy diagram for hydrogen adsorption at different catalytic sites on $\mathrm{La}_{2} \mathrm{Sr}_{2} \mathrm{PtO}_{7+\delta}$ and $\mathrm{Pt}$ (111). c The kinetic energy barrier of hydrogen migration/spillover process for $\mathrm{La}_{2} \mathrm{Sr}_{2} \mathrm{PtO}_{7+\delta}$. (IS the initial state, TS the transition state, FS the final state). d The free energy profiles of Heyrovsky step in HER on $\mathrm{La}_{2} \mathrm{Sr}_{2} \mathrm{PtO}_{7+\delta}$ (with and without hydrogen migration/spillover). e Schematic illustration of catalysis mechanism for acidic $\mathrm{HER}$ via atomic-scale hydrogen spillover on the $\mathrm{La}_{2} \mathrm{Sr}_{2} \mathrm{PtO}_{7+\delta}$ oxide.

The recorded Nyquist plots were simulated by a double-parallel equivalent circuit model (Fig. 5d, Supplementary Fig. 22 and Table 4). Following a previous recognition, the second parallel component $R_{2}$ ( $R_{2}$ represents the hydrogen adsorption resistance) can reflect the hydrogen adsorption behavior on catalyst surface ${ }^{24,57}$. In view of the potential-dependent $R_{2}$ for all catalysts, it is reasonable to quantify their hydrogen adsorption kinetics via plotting $\log R_{2}$ vs. overpotential and calculating the EIS-derived Tafel slopes by virtue of the Ohm's law ${ }^{57,59}$. As displayed in Fig. 5e, the decreased slope for $\mathrm{La}_{2} \mathrm{Sr}_{2} \mathrm{PtO}_{7+\delta}$ indicates an accelerated hydrogen adsorption kinetics, which may be associated with the promoted hydrogen spillover ${ }^{57}$.

Furthermore, H/D kinetic isotope effects (KIEs) can reflect the hydrogen or proton transfer kinetic information of chemical reactions, and the presence of KIEs (KIEs > 1.5) is considered as evidence that proton or hydrogen transfer is involved to affect the reaction rate ${ }^{60-63}$. The KIEs experiment in $0.5 \mathrm{M} \mathrm{D}_{2} \mathrm{SO}_{4} / \mathrm{D}_{2} \mathrm{O}$ solution was performed to obtain insight into the role of hydrogen transfer during the HER. The polarization curve of $\mathrm{La}_{2} \mathrm{Sr}_{2} \mathrm{PtO}_{7+\delta}$ in $0.5 \mathrm{M} \mathrm{D}_{2} \mathrm{SO}_{4} / \mathrm{D}_{2} \mathrm{O}$ solution exhibits significantly lower current density in comparison with that of $\mathrm{La}_{2} \mathrm{Sr}_{2} \mathrm{PtO}_{7+\delta}$ in the $0.5 \mathrm{M} \mathrm{H}_{2} \mathrm{SO}_{4} / \mathrm{H}_{2} \mathrm{O}$ solution by a factor about $2.2-2.6$ $(\mathrm{KIEs}=2.2-2.6)$ over the entire potential range (Fig. 5e). The KIEs value of $\mathrm{La}_{2} \mathrm{Sr}_{2} \mathrm{PtO}_{7+\delta}$ suggests that the hydrogen or proton transfer involved in HER process is one possible step affecting the reaction rate.

Overall, the above experiments collectively verify the possible occurrence of hydrogen spillover in $\mathrm{La}_{2} \mathrm{Sr}_{2} \mathrm{PtO}_{7+\delta}$. Currently, it's very difficult to directly observe the electrocatalytic hydrogen spillover phenomenon, but we expect that in the future it could be resolved with the development of more advanced methodologies and technologies, such as transient imaging technology with super-high spatial resolution and nano-sized three-electrode electrochemical system.
DFT calculations. To gain atomic-scale insight into the origin of the exceptional intrinsic activity of $\mathrm{La}_{2} \mathrm{Sr}_{2} \mathrm{PtO}_{7+\delta}$ for HER in acid, density functional theory (DFT) calculations were carried out. Based on prior structural data and the analysis of HRTEM and SAED, (001) surface slab models with different terminations of $\mathrm{La}_{2} \mathrm{Sr}_{2} \mathrm{PtO}_{7+\delta}$ and the optimized structures are shown in Fig. 6a and Supplementary Fig. 23. Generally, the acidic HER process involves a three-state diagram with an initial proton $\left(\mathrm{H}^{+}\right)$, an intermediate adsorbed $\mathrm{H}^{*}$ and a final $\mathrm{H}_{2}$ state, and the hydrogen adsorption Gibbs free energy $\left(\Delta \mathrm{G}_{\mathrm{H}^{*}}\right)$ is taken as a commonlyaccepted descriptor for accessing the intrinsic activity of electrocatalysts toward acid HER ${ }^{64,65}$. According to the Sabatier principle, the thermo-neutral active sites with an optimal $\left|\Delta \mathrm{G}_{\mathrm{H}^{*}}\right|$ value close to zero can facilely promote the adsorption and desorption process during HER ${ }^{25,66}$. Figure $6 \mathrm{~b}$ shows the free energy diagram of $\mathrm{La}_{2} \mathrm{Sr}_{2} \mathrm{PtO}_{7+\delta}$ on all the possible sites at the terminations of Pt-O-La, La-O and Sr-O along with Pt (111) metal as a reference. It is found that the $\mathrm{H}$ adsorption on the sites of La-O and $\mathrm{Sr}-\mathrm{O}$ terminations is all too strong, which is not beneficial HER. On the Pt-O-La termination, the $\Delta \mathrm{G}_{\mathrm{H}^{*}}$ values on $\mathrm{O}$ and Pt sites are -0.61 and $1.96 \mathrm{eV}$, respectively, indicating that the $\mathrm{H}$ adsorption is either too strong or too weak. Impressively, the calculated $\mathrm{G}_{\mathrm{H}^{*}}$ for the unique La-Pt bridge site is $0.11 \mathrm{eV}$, an optimal value close to a thermo-neutral state even exceeding that $(-0.16 \mathrm{eV})$ for the state-of-art Pt (111) surface, suggesting the hydrogen adsorption is neither too strong nor too weak. Thus, the Pt-O-La termination of $\mathrm{La}_{2} \mathrm{Sr}_{2} \mathrm{PtO}_{7+\delta}$ with three different $\mathrm{H}$ adsorption sites is chosen for studying the HER process.

As reported before, hydrogen spillover has been an efficient strategy to boost the intrinsic HER activity of the binary-component electrocatalysts ${ }^{21-24}$. These HSBCCs generally consist of one hydrogen-enriched component with a negative $\Delta \mathrm{G}_{\mathrm{H}^{*}}$ value and one hydrogen-poor component with a positive $\Delta \mathrm{G}_{\mathrm{H}^{*}}$ value, and hydrogen spillover takes place from the surface with $\Delta \mathrm{G}_{\mathrm{H}-\text { negative }}$ to 
the surface with $\Delta \mathrm{G}_{\mathrm{H} \text {-positive }}{ }^{23,24}$. When a single-component catalyst contains more than one kind of catalytic site, the hydrogen spillover effect between different sites may also happen and can affect the overall catalytic activity. With regard to single-component $\mathrm{La}_{2} \mathrm{Sr}_{2} \mathrm{PtO}_{7+\delta}$ catalyst, the $\mathrm{H}^{+}$preferentially adsorbs at $\mathrm{O}$ site among three possible sites (i.e., $\mathrm{O}$ site, La-Pt bridge site and $\mathrm{Pt}$ site) due to the negative $\Delta \mathrm{G}_{\mathrm{H}^{*}}$ value of $-0.61 \mathrm{eV}$, suggesting significant proton trapping at $\mathrm{O}$ site which functions as hydrogen-enriched "component". Conversely, the $\mathrm{H}$ exhibits weak adsorption on the $\mathrm{Pt}$ site with $\Delta \mathrm{G}_{\mathrm{H}^{*}}$ value of $1.96 \mathrm{eV}$, indicating Pt site with high oxidation state resembles the hydrogen-poor "component" and is advantageous for $\mathrm{H}_{2}$ desorption. More importantly, the thermoneutral La-Pt bridge site can serve as the mediator for favorable hydrogen spillover, similar to the interface site in the conventional HSBCCs. In view of the steadily weakened $\mathrm{H}$ adsorption, a feasible channel for the hydrogen spillover from $\mathrm{O}$ site $\rightarrow \mathrm{La}-\mathrm{Pt}$ bridge site $\rightarrow \mathrm{Pt}$ site may be formed on the $\mathrm{La}_{2} \mathrm{Sr}_{2} \mathrm{PtO}_{7+\delta}$ catalyst. Noticeably, the interface-free feature and short reaction distance within the crystal lattice on single-phase $\mathrm{La}_{2} \mathrm{Sr}_{2} \mathrm{PtO}_{7+\delta}$ catalyst is beneficial for minimizing the kinetic barrier for hydrogen spillover $^{52,67}$, somewhat analogous to the reported metal alloy system with low hydrogen spillover barrier ${ }^{68-71}$. The calculation shows that the hydrogen spillover step has a low energy barrier value of $0.22 \mathrm{eV}$ (Fig. $6 \mathrm{c}$ and Supplementary Fig. 24), indicating that the $\mathrm{H}$ migration from $\mathrm{O}$ site to $\mathrm{Pt}$ site is a kinetically favorable process. Then, we calculated the energy barriers of Heyrovsky step with and without hydrogen spillover. As seen from Fig. 6d, the energy barrier on $\mathrm{Pt}$ site after $\mathrm{H}$ migration is $0.17 \mathrm{eV}$, which is lower than that $(0.26 \mathrm{eV})$ on $\mathrm{O}$ site without $\mathrm{H}$ migration, demonstrating the superiority of hydrogen spillover/migration of $\mathrm{La}_{2} \mathrm{Sr}_{2} \mathrm{PtO}_{7+\delta}$ for HER catalysis. It should be also noted that the theoretical overpotential $(0.22 \mathrm{~V})$ of $\mathrm{La}_{2} \mathrm{Sr}_{2} \mathrm{PtO}_{7+\delta}$ for the whole HER process involving the hydrogen spillover is lower than that $(0.69 \mathrm{~V})$ for the conventional HER mechanism on Pt surface ${ }^{72}$. Based on these DFT results, a possible HER catalytic mechanism on $\mathrm{La}_{2} \mathrm{Sr}_{2} \mathrm{PtO}_{7+\delta}$ in acidic media via the synergy of multi-function catalytic sites was proposed, as schematically illustrated in Fig. 6e. Namely, the $\mathrm{O}$ site serves as the proton enrichment, the thermo-neutral La-Pt bridge site serves as the mediator for favorable hydrogen spillover/ migration from $\mathrm{O}$ site to $\mathrm{Pt}$ site, and $\mathrm{Pt}$ site functions the final $\mathrm{H}_{2}$ desorption. In order to further confirm the active sites of $\mathrm{La}_{2} \mathrm{Sr}_{2} \mathrm{PtO}_{7+\delta}$ for HER, poisoning tests was performed by adding thiocyanate $\left(\mathrm{SCN}^{-}\right)$and tetramethylammonium cation $\left(\mathrm{TMA}^{+}\right)$ ions into acidic solutions (Supplementary Fig. 25) ${ }^{73,74}$. The $\mathrm{La}_{2} \mathrm{Sr}_{2} \mathrm{PtO}_{7+\delta}$ exhibits evident performance decay after adding $\mathrm{SCN}^{-}$or $\mathrm{TMA}^{+}$into $\mathrm{H}_{2} \mathrm{SO}_{4}$ solution, indicating that the $\mathrm{Pt}$ and $\mathrm{O}$ ions are both active sites of $\mathrm{La}_{2} \mathrm{Sr}_{2} \mathrm{PtO}_{7+\delta}$ for HER. However, Pt/ $\mathrm{WO}_{3}$ shows evident activity loss after adding $\mathrm{SCN}^{-}$and has nearly no activity loss after adding $\mathrm{TMA}^{+}$, implying that the metallic $\mathrm{Pt}$ is the sole active site. Such result demonstrates the direct actives of $\mathrm{Pt}$ and $\mathrm{O}$ ions for $\mathrm{HER}$ in $\mathrm{La}_{2} \mathrm{Sr}_{2} \mathrm{PtO}_{7+\delta}$, which is initiated by the hydrogen spillover/migration and accordingly contributes to the high performance.

\section{Discussion}

In summary, we have successfully synthesized a single-phase complex oxide $\mathrm{La}_{2} \mathrm{Sr}_{2} \mathrm{PtO}_{7+\delta}$ with exceptional HER performance in acid medium via a facile and scalable solid-state reaction method. The $\mathrm{La}_{2} \mathrm{Sr}_{2} \mathrm{PtO}_{7+\delta}$ displays an excellent HER activity with an ultralow overpotential of $13 \mathrm{mV}$ at a current density of $10 \mathrm{~mA} \mathrm{~cm}^{-2}$ and a small Tafel slope of $22 \mathrm{mV} \mathrm{dec}^{-1}$ in $0.5 \mathrm{M}$ $\mathrm{H}_{2} \mathrm{SO}_{4}$ solution, surpassing state-of-the-art Pt-based catalysts and HSBCC ever reported. Besides, significant intrinsic activity and durability enhancement were observed for $\mathrm{La}_{2} \mathrm{Sr}_{2} \mathrm{PtO}_{7+\delta}$ relative to the commercial Pt black. By coupling DFT simulations and comprehensive experiments, the high HER catalytic activity of $\mathrm{La}_{2} \mathrm{Sr}_{2} \mathrm{PtO}_{7+\delta}$ in acid possibly results from an unusual atomicscale hydrogen spillover effect between multiple catalytic sites, whereby $\mathrm{O}$ site captures proton, $\mathrm{H}$ facilely diffuses from $\mathrm{O}$ site to Pt site with thermoneutral La-Pt bridge site serving as the mediator, and eventually as-formed $\mathrm{H}_{2}$ favorably releases on Pt site. Our proof-of-concept investigations not only provides the atomic-level insight into the hydrogen spillover within $\mathrm{La}_{2} \mathrm{Sr}_{2} \mathrm{PtO}_{7+\delta}$ for acidic HER, but also open a new avenue for the design of advanced electrocatalysts via constructing multifunctional catalytic sites.

\section{Methods}

Catalyst synthesis. $\mathrm{La}_{2} \mathrm{Sr}_{2} \mathrm{PtO}_{7+\delta}$ catalyst was synthesized via the traditional solid-phase reaction method. Firstly, stoichiometric amounts of $\mathrm{La}_{2} \mathrm{O}_{3}, \mathrm{SrCO}_{3}$, and Pt were weighed and mixed in ethanol and water under the rotation speed of $400 \mathrm{rpm}$ for $1 \mathrm{~h}$ through the high-energy ball-milling (Planetary Mono Mill, Pulverisette 6 , Fritsch). Then the homogeneously dispersed mixture was dried and finally calcined at $1100{ }^{\circ} \mathrm{C}$ in air for $10 \mathrm{~h}$ to obtain the resultant catalyst powders $\mathrm{Pt} / \mathrm{WO}_{3}$ complex catalyst was prepared via the high-energy ball-milling method. In detail, $\mathrm{WO}_{3}$ and $\mathrm{Pt}$ were weighed at mass ratio of 75:25 and mixed in ethanol and water under the rotation speed of $400 \mathrm{rpm}$ for $1 \mathrm{~h}$ through the high-energy ballmilling. The homogeneously dispersed mixture was finally dried to obtain the resultant catalyst powders.

Characterizations. XRD patterns were measured using a Rigaku Smartlab diffractometer operating at $40 \mathrm{kV}$ with filtered $\mathrm{Cu} \mathrm{Ka}$ radiation. The Rietveld refinements were revealed using DIFFRAC plus Topas 4.2 software. SEM images were recorded through a scanning electron microscope equipped with the scanning electron microanalyzer (Hitachi S-4800). The HRTEM images were obtained utilizing the electron microscope (FEI Tecnai G2 F20) operating at $200 \mathrm{kV}$. STEM image and elemental mapping images were obtained using Tecnai F20 SuperTwin operating at $200 \mathrm{kV}$. Nitrogen adsorption-desorption isotherms were recorded on BELSORP II. Pt4f spectra were acquired on XPS (Perkin Elmer PHI 1600 ECSA system). X-ray absorption near-edge structure (XANES) and the EXAFS spectra were determined at the BL 07A beamline of the National Synchrotron Radiation Research Center in Taiwan. All samples were pretreated via cutting pellets in an ultrahigh vacuum chamber to obtain a clean surface. Hydrogen temperatureprogrammed desorption $\left(\mathrm{H}_{2}-\mathrm{TPD}\right)$ experiments were performed on Chembet Pulsar (Quantachrome Instruments, USA). In total, $50 \mathrm{mg}$ of sample was pretreated at $200^{\circ} \mathrm{C}$ for $3 \mathrm{~h}$ in hydrogen atmosphere and then was cleaned with argon gas flow at $50{ }^{\circ} \mathrm{C}$ for $30 \mathrm{~min}$ to remove weakly adsorbed $\mathrm{H}_{2}$. TPD process was performed by heating the sample from 50 to $600{ }^{\circ} \mathrm{C}$ at a ramp rate of $2.5^{\circ} \mathrm{C} \mathrm{min}{ }^{-1}$ under argon atmosphere.

Electrochemical measurements. HER measurements in acid media were conducted in a standard three-electrode electrochemical cell (Pine Research Instrumentation) in an RDE configuration using a CHI 760E electrochemistry workstation. Catalysts cast on $\mathrm{RDE}$ ( $5 \mathrm{~mm}$ in diameter), graphite rod, and $\mathrm{Ag} \mid \mathrm{AgCl}$ $(3.5 \mathrm{M} \mathrm{KCl})$ were used as the working electrode, counter electrode, and reference electrode, respectively. Working electrodes for HER measurements were prepared by a controlled drop-casting method, in accordance with the previous works ${ }^{2,64}$. The mass loading of oxide catalysts and Pt black on the RDE is $\sim 0.232$ and $0.058 \mathrm{mg} \mathrm{cm}^{-2}$, respectively. Linear sweep voltammetry was recorded at $5 \mathrm{mV} \mathrm{s}^{-1}$ at the rotation of $2400 \mathrm{rpm}$ in $\mathrm{Ar}$ or $\mathrm{H}_{2}$-saturated $0.5 \mathrm{M} \mathrm{H}_{2} \mathrm{SO}_{4}$. Tafel slopes were determined by plotting the overpotential vs. the logarithm of current density $(\log |j|)$. CV curves involving in the $\mathrm{H}_{\text {upd }}$ adsorption/desorption peak were obtained in $\mathrm{N}_{2}$-saturated $0.5 \mathrm{M} \mathrm{H}_{2} \mathrm{SO}_{4}$ solution with potential window between $0.05 \mathrm{~V}$ and $1.1 \mathrm{~V}$ vs. RHE and a sweep rate of $100 \mathrm{mV} \mathrm{s}^{-1}$. The ECSA was derived from the $\mathrm{H}_{\text {upd }}$ desorption peak $(0.03-0.35 \mathrm{~V})$ area normalized by the total mass of the Pt element. ADT of catalysts was conducted through continuous potential cycling ranged from 0 to $-0.4 \mathrm{~V}$ vs. $\mathrm{Ag} \mid \mathrm{AgCl}$ for 1000 cycles at a scan rate of $100 \mathrm{mV} \mathrm{s}^{-1}$. The chronopotentiometry tests were performed at a constant cathodic current density of $10 \mathrm{~mA} \mathrm{~cm}^{-2}$ to explore the durability of the electrocatalysts. EIS measurements were carried out on the Bio-Logic SP-300 workstation at RT in the frequency range of $100 \mathrm{kHz}-0.1 \mathrm{~Hz}$ at various $\mathrm{HER}$ overpotentials.

Computational methods. All first-principle calculations were performed using DFT implemented in the Vienna Ab initio Simulation Package. The projector augmented wave pseudo potentials with the Perdew-Burke-Enrnzerhof functional were used. The cutoff of kinetic energy was set as $500 \mathrm{eV}$. $\mathrm{La}_{2} \mathrm{Sr}_{2} \mathrm{PtO}_{7}$ bulk with R-3 space group was built for lattice structure optimization. Monkhorst-Pack $7 \times 7 \times 2$ $k$-point mesh was used during the structure relaxation. (001) surface slab models with different terminations were cleaved from the optimized bulk lattice to investigate $\mathrm{H}$ adsorption on surface. A $15 \AA$-thick vacuum layer was added to the surface in the $z$ direction. In total, $2 \times 2$ supercells were built to simulate HER 
process on (001) surface with La-O-Pt termination. Half layers on the bottom were fixed to mimic bulk arrangements, while other layers were fully relaxed to represent surface features. The first Brillouin zone of the slab model was samples with a $5 \times 5 \times 1 k$-point grid. The first Brillouin zone of the slab model and supercell was sampled with a $5 \times 5 \times 1$ and a $3 \times 3 \times 1 k$-point grid, respectively. Transition states were determined using climbing image nudge elastic band method with 8 images. All calculations were performed in a spin-polarized fashion. The force and energy convergence criteria were set to $0.02 \mathrm{eV}^{-1}$ and $10^{-5} \mathrm{e} \AA$, respectively. Zero-point energy and entropy corrections were introduced for Gibbs energy calculations.

Reporting summary. Further information on research design is available in the Nature Research Reporting Summary linked to this article.

\section{Data availability}

The data that support the findings of this study are available in the Source Data. Source data are provided with this paper.

Received: 30 June 2021; Accepted: 11 February 2022;

Published online: 04 March 2022

\section{References}

1. Podjaski, F. et al. Rational strain engineering in delafossite oxides for highly efficient hydrogen evolution catalysis in acidic media. Nat. Catal. 3, 55-63 (2019).

2. Dai, J. et al. Single-phase perovskite oxide with super-exchange induced atomic-scale synergistic active centers enables ultrafast hydrogen evolution. Nat. Commun. 11, 5657 (2020)

3. She, Z. W. et al. Two-dimensional molybdenum carbide (MXene) as an efficient electrocatalyst for hydrogen evolution. ACS Energy Lett. 1, 589-594 (2016).

4. Chen, X., Jin, X., Ling, X. \& Wang, Y. Indirect integration of thermochemical energy storage with the recompression supercritical $\mathrm{CO}_{2}$ Brayton cycle. Energy 209, 118452 (2020).

5. Wang, Z. et al. Low-iridium-content IrNiTa metallic glass films as intrinsically active catalysts for hydrogen evolution reaction. Adv. Mater. 32, e1906384 (2020).

6. Cheng, L. et al. Ultrathin $\mathrm{WS}_{2}$ nanoflakes as a high-performance electrocatalyst for the hydrogen evolution reaction. Angew. Chem. Int. Ed. 53, 7860-7863 (2014).

7. Zhu, Y. et al. Metal oxide-based materials as an emerging family of hydrogen evolution electrocatalysts. Energy Environ. Sci. 13, 3361-3392 (2020).

8. Reier, T., Nong, H. N., Teschner, D., Schlögl, R. \& Strasser, P. Electrocatalytic oxygen evolution reaction in acidic environments-reaction mechanisms and catalysts. Adv. Energy Mater. 7, 1601275 (2017).

9. Kibsgaard, J. \& Jaramillo, T. F. Molybdenum phosphosulfide: an active, acidstable, earth-abundant catalyst for the hydrogen evolution reaction. Angew. Chem. Int. Ed. 53, 14433-14437 (2014).

10. Zhu, Y. et al. Tailored brownmillerite oxide catalyst with multiple electronic functionalities enables ultrafast water oxidation. Chem. Mater. 33, 5233-5241 (2021).

11. Han, N. et al. Nitrogen-doped tungsten carbide nanoarray as an efficient bifunctional electrocatalyst for water splitting in acid. Nat. Commun. 9, 924 (2018).

12. Kucernak, A. R. J. \& Naranammalpuram Sundaram, V. N. Nickel phosphide: the effect of phosphorus content on hydrogen evolution activity and corrosion resistance in acidic medium. J. Mater. Chem. A 2, 17435-17445 (2014)

13. Cheng, $\mathrm{X}$. et al. Highly active, stable oxidized platinum clusters as electrocatalysts for the hydrogen evolution reaction. Energy Environ. Sci. 10, 2450-2458 (2017).

14. $\mathrm{Su}$, J. et al. Ruthenium-cobalt nanoalloys encapsulated in nitrogen-doped graphene as active electrocatalysts for producing hydrogen in alkaline media. Nat. Commun. 8, 14969 (2017).

15. Li, Y. et al. Local atomic structure modulations activate metal oxide as electrocatalyst for hydrogen evolution in acidic water. Nat. Commun. 6, 8064 (2015).

16. Zheng, X. et al. Multifunctional active-center-transferable platinum/lithium cobalt oxide heterostructured electrocatalysts towards superior water splitting. Angew. Chem. Int. Ed. 59, 14533-14540 (2020).

17. Liu, D. et al. Atomically dispersed platinum supported on curved carbon supports for efficient electrocatalytic hydrogen evolution. Nat. Energy 4, 512-518 (2019).

18. Kobayashi, D. et al. Significant enhancement of hydrogen evolution reaction activity by negatively charged Pt through light doping of W. J. Am. Chem. Soc. 142, 17250-17254 (2020).
19. Cao, Z. et al. Platinum-nickel alloy excavated nano-multipods with hexagonal close-packed structure and superior activity towards hydrogen evolution reaction. Nat. Commun. 8, 15131 (2017).

20. $\mathrm{Xu}, \mathrm{G}$.-R. et al. Polyallylamine-functionalized platinum tripods: enhancement of hydrogen evolution reaction by proton carriers. ACS Catal. 7, 452-458 (2016).

21. Park, J. et al. Investigation of the support effect in atomically dispersed Pt on $\mathrm{WO}_{3-\mathrm{x}}$ for utilization of $\mathrm{Pt}$ in the hydrogen evolution reaction. Angew. Chem. Int. Ed. 58, 16038-16042 (2019).

22. Esposito, D. V., Levin, I., Moffat, T. P. \& Talin, A. A. $\mathrm{H}_{2}$ evolution at Si-based metal-insulator-semiconductor photoelectrodes enhanced by inversion channel charge collection and H spillover. Nat. Mater. 12, 562-568 (2013).

23. Liu, T. et al. Selective loading of atomic platinum on a $\mathrm{RuCeO}_{\mathrm{x}}$ support enables stable hydrogen evolution at high current densities. Angew. Chem. Int. Ed. 59, 20423-20427 (2020).

24. Li, J. et al. Ethylene-glycol ligand environment facilitates highly efficient hydrogen evolution of $\mathrm{Pt} / \mathrm{CoP}$ through proton concentration and hydrogen spillover. Energy Environ. Sci. 12, 2298-2304 (2019).

25. Guan, D. et al. Searching general sufficient-and-necessary conditions for ultrafast hydrogen-evolving electrocatalysis. Adv. Funct. Mater. 29, 1900704 (2019).

26. Wang, P., Jiang, K., Wang, G., Yao, J. \& Huang, X. Phase and interface engineering of platinum-nickel nanowires for efficient electrochemical hydrogen evolution. Angew. Chem. Int. Ed. 55, 12859-12863 (2016).

27. Wang, Y., Chen, L., Yu, X., Wang, Y. \& Zheng, G. Superb alkaline hydrogen evolution and simultaneous electricity generation by Pt-decorated $\mathrm{Ni}_{3} \mathrm{~N}$ nanosheets. Adv. Energy Mater. 7, 1601390 (2017)

28. Zhang, L. et al. N-modified $\mathrm{NiO}$ surface for superior alkaline hydrogen evolution. ChemSusChem 11, 1020-1024 (2018).

29. Zhao, D. et al. Synergistically interactive pyridinic-N-MoP sites: identified active centers for enhanced hydrogen evolution in alkaline solution. Angew. Chem. Int. Ed. 59, 8982-8990 (2020).

30. Grimaud, A. et al. Activation of surface oxygen sites on an iridium-based model catalyst for the oxygen evolution reaction. Nat. Energy 2, 16189 (2016).

31. Miao, X. et al. Quadruple perovskite ruthenate as a highly efficient catalyst for acidic water oxidation. Nat. Commun. 10, 3809 (2019).

32. Zhu, Y. et al. Boosting oxygen evolution reaction by creating both metal ion and lattice-oxygen active sites in a complex oxide. Adv. Mater. 32, 1905025 (2020).

33. Ebbinghaus, S. G., Erztoument, C. \& Marozau, I. $\mathrm{Ln}_{2} \mathrm{Sr}_{2} \mathrm{PtO}_{7+\delta}(\mathrm{Ln}=\mathrm{La}, \mathrm{Pr}$, and $\mathrm{Nd}$ ): three new Pt-containing $\left[\mathrm{A}_{\mathrm{n}} \mathrm{B}_{\mathrm{n}-1} \mathrm{O}_{3 \mathrm{n}}\right]$-type hexagonal perovskites. $J$ Solid. State Chem. 180, 3393-3400 (2007).

34. Wang, Z. et al. A platinum oxide decorated amorphous cobalt oxide hydroxide nanosheet array towards alkaline hydrogen evolution. J. Mater. Chem. A 6, 3864-3868 (2018)

35. Agrestini, S. et al. Nature of the magnetism of iridium in the double perovskite $\mathrm{Sr}_{2} \mathrm{CoIrO}_{6}$. Phys. Rev. B 100, 014443 (2019).

36. Chen, J. et al. Enhanced magnetization of the highest- $T_{C}$ ferrimagnetic oxide $\mathrm{Sr}_{2} \mathrm{CrOsO}_{6}$. Phys. Rev. B 102, 184418 (2020).

37. Zhu, Y. et al. Single-atom in-doped subnanometer Pt nanowires for simultaneous hydrogen generation and biomass upgrading. Adv. Funct. Mater. 30, 2004310 (2020)

38. $\mathrm{Pi}, \mathrm{Y}$. et al. Selective surface reconstruction of a defective iridium-based catalyst for high-efficiency water splitting. Adv. Funct. Mater. 30, 2004375 (2020).

39. Zhuang, L. et al. Defect-induced Pt-Co-Se coordinated sites with highly asymmetrical electronic distribution for boosting oxygen-involving electrocatalysis. Adv. Mater. 31, 1805581 (2019).

40. Lu, F. et al. Engineering platinum-oxygen dual catalytic sites via charge transfer towards high-efficient hydrogen evolution. Angew. Chem. Int. Ed. 59, 17712 (2020).

41. Cheng, N. et al. Platinum single-atom and cluster catalysis of the hydrogen evolution reaction. Nat. Commun. 7, 13638 (2016).

42. Sheng, W. et al. Non-precious metal electrocatalysts with high activity for hydrogen oxidation reaction in alkaline electrolytes. Energy Environ. Sci. 7, 1719-1724 (2014)

43. Pan, Y. et al. Cobalt nickel phosphide nanoparticles decorated carbon nanotubes as advanced hybrid catalysts for hydrogen evolution. J. Mater. Chem. A 4, 14675-14686 (2016).

44. She, Z. W. et al. Combining theory and experiment in electrocatalysis: insights into materials design. Science 355, eaad4998 (2017)

45. Lim, B. et al. Pd-Pt bimetallic nanodendrites with high activity for oxygen reduction. Science 324, 1302-1305 (2009)

46. $\mathrm{Li}, \mathrm{M}$. et al. Ultrafine Jagged platinum nanowires enable ultrahigh mass activity for the oxygen reduction reaction. Science 354, 1414-1419 (2016).

47. Kibsgaard, J. et al. Designing an improved transition metal phosphide catalyst for hydrogen evolution using experimental and theoretical trends. Energy Environ. Sci. 8, 3022-3029 (2015). 
48. Mahmood, J. et al. An efficient and pH-universal ruthenium-based catalyst for the hydrogen evolution reaction. Nat. Nanotech. 12, 441-446 (2017).

49. Cao, X. et al. Highly catalytic active PtNiCu nanochains for hydrogen evolution reaction. Nano Energy 9, 301-308 (2014).

50. Katsounaros, I., Cherevko, S., Zeradjanin, A. R. \& Mayrhofer, K. J. J. Oxygen electrochemistry as a cornerstone for sustainable energy conversion. Angew. Chem. Int. Ed. 53, 102-121 (2014).

51. Zhu, Y., Zhou, W. \& Shao, Z. Perovskite/carbon composites: applications in oxygen electrocatalysis. Small 13, 1603793 (2017).

52. Xiong, M. et al. In situ tuning of electronic structure of catalysts using controllable hydrogen spillover for enhanced selectivity. Nat. Commun. 11, 4773 (2020).

53. Khoobiar, S. Particle to particle migration of hydrogen atoms on platinumalumina catalysts from particle to neighboring particles. J. Phys. Chem. 68, 411-412 (1964).

54. Zhu, L. et al. A rhodium/silicon co-electrocatalyst design concept to surpass platinum hydrogen evolution activity at high overpotentials. Nat. Commun. 7, $12272(2016)$

55. Cheng, Y. et al. $\mathrm{Rh} / \mathrm{MoS}_{2}$ nanocomposite catalysts with Pt-like activity for hydrogen evolution reaction. Adv. Funct. Mater. 27, 1700359 (2017).

56. Sheng, M. et al. Approaching the volcano top: iridium/silicon nanocomposites as efficient electrocatalysts for the hydrogen evolution reaction. ACS Nano 13, 2786-2794 (2019).

57. $\mathrm{Li}$, J. et al. A fundamental viewpoint on the hydrogen spillover phenomenon of electrocatalytic hydrogen evolution. Nat. Commun. 12, 3502 (2021).

58. Zhan, D., Velmurugan, J. \& Mirkin, M. V. Adsorption/desorption of hydrogen on Pt nanoelectrodes: evidence of surface diffusion and spillover. J. Am. Chem. Soc. 131, 14756-14760 (2009).

59. Damian, A. \& Omanovic, S. Ni and NiMo hydrogen evolution electrocatalysts electrodeposited in a polyaniline matrix. J. Power Sources 158, 464-476 (2006).

60. Li, W. et al. A bio-inspired coordination polymer as outstanding water oxidation catalyst via second coordination sphere engineering. Nat. Commun. 10, 5074 (2019).

61. Coggins, M. K., Zhang, M.-T., Chen, Z., Song, N. \& Meyer, T. J. Single-site copper(II) water oxidation electrocatalysis: rate enhancements with $\mathrm{HPO}_{4}{ }^{2-}$ as a proton acceptor at pH 8. Angew. Chem. Int. Ed. 53, 12226-12230 (2014).

62. Lewandowska-Andralojc, A. et al. Kinetic and mechanistic studies of carbonto-metal hydrogen atom transfer involving Os-centered radicals: evidence for tunneling. J. Am. Chem. Soc. 136, 3572-3578 (2014).

63. Li, H., Xie, F. \& Zhang, M.-T. Metal-free electrocatalyst for water oxidation initiated by hydrogen atom transfer. ACS Catal. 11, 68-73 (2021).

64. Zhu, Y. et al. Unusual synergistic effect in layered Ruddlesden-Popper oxide enables ultrafast hydrogen evolution. Nat. Commun. 10, 149 (2019).

65. Yang, Y. et al. O-coordinated W-Mo dual-atom catalyst for $\mathrm{pH}$-universal electrocatalytic hydrogen evolution. Sci. Adv. 6, eaba6586 (2020).

66. Zhou, Y. et al. Enhanced performance of in-plane transition metal dichalcogenides monolayers by configuring local atomic structures. Nat. Commun. 11, 2253 (2020).

67. Sha, X., Chen, L., Cooper, A. C., Pez, G. P. \& Cheng, H. Hydrogen absorption and diffusion in bulk $\alpha-\mathrm{MoO}_{3}$. J. Phys. Chem. C. 113, 11399-11407 (2009).

68. Marcinkowski, M. D. et al. Controlling a spillover pathway with the molecular cork effect. Nat. Mater. 12, 523-528 (2013).

69. Shen, F. et al. Bimetallic iron-iridium alloy nanoparticles supported on nickel foam as highly efficient and stable catalyst for overall water splitting at large current density. Appl. Catal. B: Environ. 278, 119327 (2020).

70. Tierney, H. L., Baber, A. E., Kitchin, J. R. \& Sykes, E. C. H. Hydrogen dissociation and spillover on individual isolated palladium atoms. Phys. Rev. Lett. 103, 246102 (2009).

71. Baber, A. E., Tierney, H. L., Lawton, T. J. \& Sykes, E. C. H. An atomic-scale view of palladium alloys and their ability to dissociate molecular hydrogen. ChemCatChem 3, 607-614 (2011).

72. Wang, D.-Y. et al. Highly active and stable hybrid catalyst of cobalt-doped $\mathrm{FeS}_{2}$ nanosheets-carbon nanotubes for hydrogen evolution reaction. J. Am. Chem. Soc. 137, 1587-1592 (2015).
73. Huang, Z.-F. et al. Chemical and structural origin of lattice oxygen oxidation in Co-Zn oxyhydroxide oxygen evolution electrocatalysts. Nat. Energy 4, 329-338 (2019)

74. Li, B.-Q., Zhao, C.-X., Liu, J.-N. \& Zhang, Q. Electrosynthesis of hydrogen peroxide synergistically catalyzed by atomic $\mathrm{Co}-\mathrm{N}_{\mathrm{x}}-\mathrm{C}$ sites and oxygen functional groups in noble-metal-free electrocatalysts. Adv. Mater. 31, 1808173 (2019).

\section{Acknowledgements}

This work was financially supported by National Natural Science Foundation of China under Nos. 21878158 and 21576135, and Priority Academic Program Development (PAPD) of Jiangsu Higher Education Institutions. Y.Z. acknowledges the Australian Research Council (Discovery Early Career Researcher Award No. DE190100005, Discovery Project No. DP200100500), and Z.H. acknowledges the support from the Max Planck-POSTECH-Hsinchu Center for Complex Phase Materials. We also acknowledge the use of instruments and scientific and technical assistance at the Monash Centre for Electron Microscopy, a Node of Microscopy Australia, and the help from Dr. Hassan A. Tahini in DFT calculations.

\section{Author contributions}

J.D., Y.Z., and Z.S. conceived and designed the research. J.D. conducted characterizations and electrochemical measurements. Y.C., Y.Z., X.W., and M.L. performed TEM characterizations. X.H.W., Z.H., and S.W. performed XAS characterizations. D.G. performed XRD refinements. Y.Z., C.Z., X.X.W., and Q.L. was involved in the structural and electrochemical analysis. Y.Z. and Y.S. was involved in the DFT calculation analysis. Y.Z. and Z.S. provided the funding support. All authors discussed and analyzed the data. J.D., Y.Z., H.W., W.Z., and Z.S. co-wrote the manuscript.

\section{Competing interests}

The authors declare no competing interests.

\section{Additional information}

Supplementary information The online version contains supplementary material available at https://doi.org/10.1038/s41467-022-28843-2.

Correspondence and requests for materials should be addressed to Yinlong Zhu or Zongping Shao.

Peer review information Nature Communications thanks Seung Woo Lee, Yong Qin and the other, anonymous, reviewer(s) for their contribution to the peer review of this work.

Reprints and permission information is available at http://www.nature.com/reprints

Publisher's note Springer Nature remains neutral with regard to jurisdictional claims in published maps and institutional affiliations.

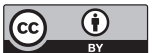

Open Access This article is licensed under a Creative Commons Attribution 4.0 International License, which permits use, sharing, adaptation, distribution and reproduction in any medium or format, as long as you give appropriate credit to the original author(s) and the source, provide a link to the Creative Commons license, and indicate if changes were made. The images or other third party material in this article are included in the article's Creative Commons license, unless indicated otherwise in a credit line to the material. If material is not included in the article's Creative Commons license and your intended use is not permitted by statutory regulation or exceeds the permitted use, you will need to obtain permission directly from the copyright holder. To view a copy of this license, visit http://creativecommons.org/ licenses/by/4.0/.

(c) The Author(s) 2022 